\title{
ASSESSING THE RELEASE OF PROPRIETARY CODE AS \\ OPEN SOURCE: LARGE COMPANY CASE
}

\author{
by \\ Xiaoling Liu \\ A thesis submitted to the Faculty of Graduate Studies and Research \\ in partial fulfillment of the requirements for the degree of \\ Master of Applied Science in Technology Innovation Management \\ Department of Systems and Computer Engineering, \\ Carleton University \\ Ottawa, Canada, K1S 5B6
}

August 2006

CCopyright 2006 Xiaoling Liu 


$\begin{array}{ll}\begin{array}{l}\text { Library and } \\ \text { Archives Canada }\end{array} & \begin{array}{l}\text { Bibliothèque et } \\ \text { Archives Canada }\end{array} \\ \begin{array}{l}\text { Published Heritage } \\ \text { Branch }\end{array} & \begin{array}{l}\text { Direction du } \\ \text { Patrimoine de l'édition }\end{array} \\ \begin{array}{l}\text { 395 Wellington Street } \\ \text { Ottawa ON K1A ON4 }\end{array} & \begin{array}{l}\text { 395, rue Wellington } \\ \text { Ottawa ON K1A ON4 } \\ \text { Canada }\end{array}\end{array}$

Your file Votre référence ISBN: 978-0-494-18325-0 Our file Notre référence ISBN: 978-0-494-18325-0

NOTICE:

The author has granted a nonexclusive license allowing Library and Archives Canada to reproduce, publish, archive, preserve, conserve, communicate to the public by telecommunication or on the Internet, loan, distribute and sell theses worldwide, for commercial or noncommercial purposes, in microform, paper, electronic and/or any other formats.

The author retains copyright ownership and moral rights in this thesis. Neither the thesis nor substantial extracts from it may be printed or otherwise reproduced without the author's permission.
AVIS:

L'auteur a accordé une licence non exclusive permettant à la Bibliothèque et Archives Canada de reproduire, publier, archiver, sauvegarder, conserver, transmettre au public par télécommunication ou par l'Internet, prêter, distribuer et vendre des thèses partout dans le monde, à des fins commerciales ou autres, sur support microforme, papier, électronique et/ou autres formats.

L'auteur conserve la propriété du droit d'auteur et des droits moraux qui protège cette thèse. $\mathrm{Ni}$ la thèse ni des extraits substantiels de celle-ci ne doivent être imprimés ou autrement reproduits sans son autorisation.
In compliance with the Canadian

Privacy Act some supporting forms may have been removed from this thesis.

While these forms may be included in the document page count, their removal does not represent any loss of content from the thesis.
Conformément à la loi canadienne sur la protection de la vie privée, quelques formulaires secondaires ont été enlevés de cette thèse.

Bien que ces formulaires aient inclus dans la pagination, il n'y aura aucun contenu manquant.

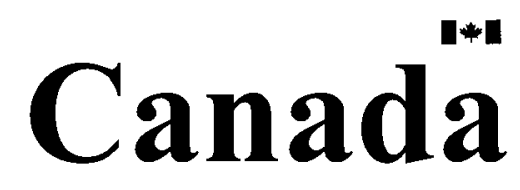




\begin{abstract}
This research uses a cooperative game theory perspective to generate insights from examining six instances of large companies releasing proprietary code as open source and makes recommendations to top management teams of large companies considering releasing their code to open source projects. The research identifies: (i) changes that occurred to the players in the company's value net; (ii) value created and appropriated by the company; (iii) open source license adopted for the code released as open source; (iv) changes to the company's business model; and (v) benefits and risks to the company releasing the code. This research will be of interest to: (i) top management teams of large companies interested in releasing code to open source projects for competitive advantages and (ii) academic researchers interested in how companies can use the release of code as open source to create and appropriate value.
\end{abstract}




\section{ACKNOWLEDGEMENTS}

I greatly acknowledge my thesis supervisor Professor Tony Bailetti for his tireless guidance, encouragement and support throughout this study. I also appreciate Professor Bailetti for always encouraging and challenging me to reach my best throughout my academic program.

I would like to express my appreciation to Professor John Callahan for his generous comments and constructive suggestions at various stages of my work.

I thank my parents and my husband for their unconditional love and continuous encouragement throughout this study, for supporting me to pursue my interests and believing in me when I doubted myself.

This thesis was developed as part of the Competing in Open Environments research program led by Tony Bailetti, Carleton University, and Peter Carbone, Nortel. The support received from Nortel for this research and the M.Eng. in Techonology Innovation Management program is gratefully acknowledged. 


\section{TABLE OF CONTENTS}

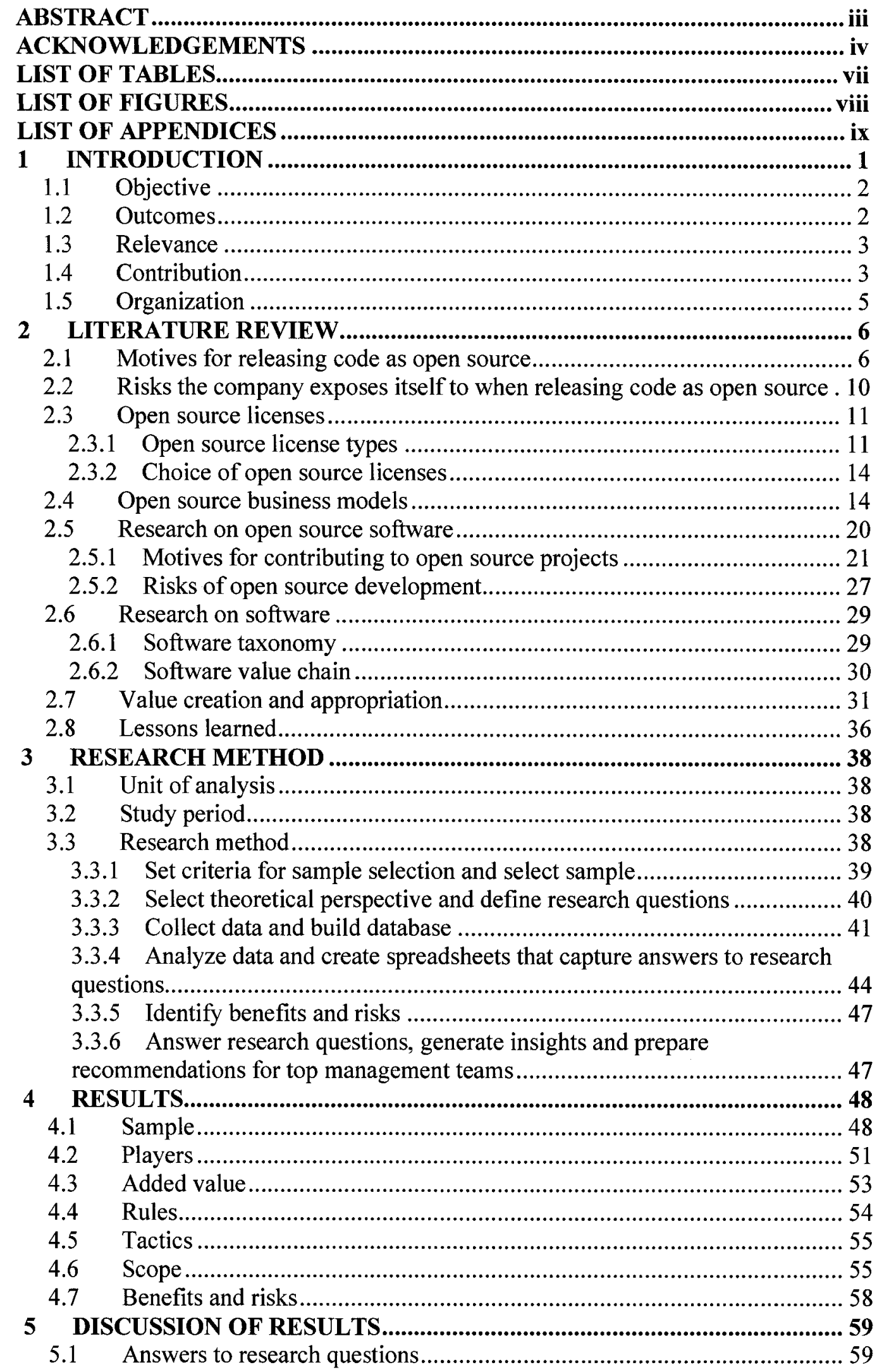


5.1.1 Changes that occur to the players in the company's value net..............6 60

5.1.2 How the company creates and appropriates value...............................6 65

5.1.3 Open source license used................................................................. 68

5.1.4 Factors that encourage and discourage external developers and third parties to contribute to the open source project...............................................69

5.1.5 Changes to the company's revenue model ........................................ 70

5.1.6 Benefits and risks of releasing code as open source ........................... 72

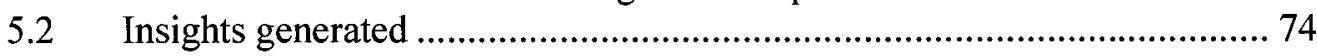

5.3 Recommendations to top management teams of large companies

considering releasing proprietary code to an open source project ........................ 83

6 CONCLUSIONS, LIMITATIONS, AND FUTURE RESEARCH .............. 87

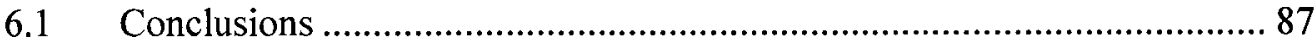

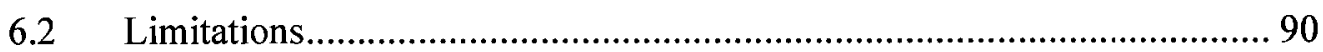

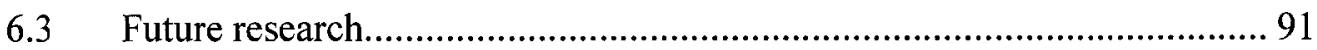

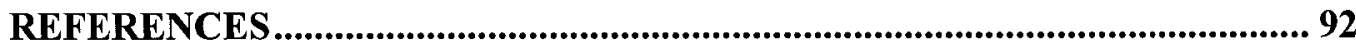

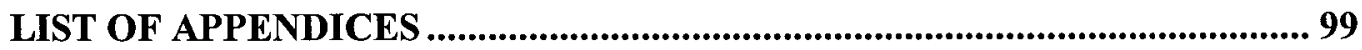




\section{LIST OF TABLES}

Table 1: Motives for releasing code as open source ............................................. 7

Table 2: Risks the company exposes itself to when releasing code as open source ... 10

Table 3: Open source business models.................................................................... 17

Table 4: Motives of firms' participating in open source projects ............................. 23

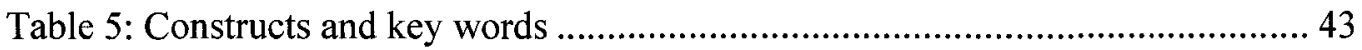

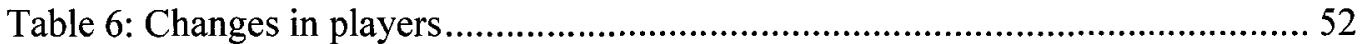

Table 7: Types of open source licenses used by large companies when they release their code as open source ............................................................................... 54

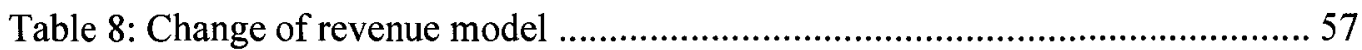




\section{LIST OF FIGURES}

Figure 1: Open source business models ......................................................... 18

Figure 2: Technical and functional software product categories ............................ 30

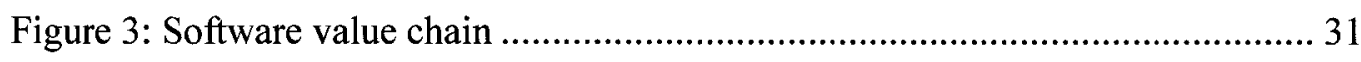

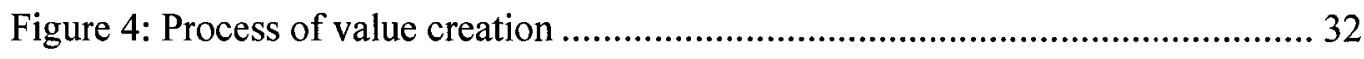

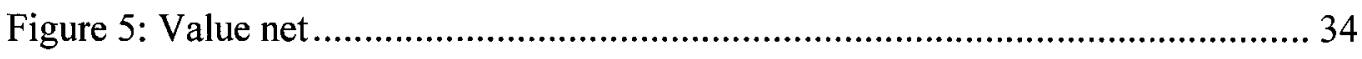

Figure 6: New players added to company's value net after code is released as open

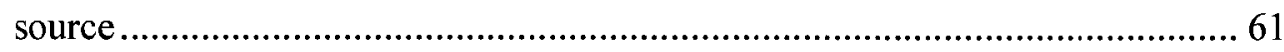

Figure 7: Value creation and value capture process for code release .......................88 88 


\section{LIST OF APPENDICES}

Appendix A: List of instances of a company releasing code to an open source project

identified using online searches .99

Appendix B: Information on the research sample 102

Appendix C: Changes in players in the company's value net 103

Appendix D: How releasing code to an open source project increases a large company's added value. 105

Appendix E: Factors that encourage or discourage developers and third parties to contribute to the open source project. 109

Appendix F: Revenue models before and after the code was released 112 Appendix G: Company related benefits and risks of releasing code as open source:114 


\section{INTRODUCTION}

Large companies such as America Online (AOL), Apple, IBM, and Sun Microsystems

$(\text { Sun })^{1}$ have released their proprietary code to open source software (OSS) projects

(Gabriel \& Goldman 2005; Hawkins, 2004). Presumably these profit seeking

companies expected the net benefits of releasing their proprietary code as open source

to be greater than the net benefits of keeping the code proprietary (Hawkins, 2004).

Hawkins (2004) has organized the existing OSS literature into: (i) advocacy works;

(ii) studies on the culture or motivation of programmers who work to produce OSS;

(iii) studies on the engineering management issues of a software production process;

and (iv) studies on the strategic motivations of firms for releasing open source

software. The latter material examines individuals, start-ups and small companies

that set up open source software projects (Yang, 2005), the splitting of software

solutions into two portions, one of which may be open source (Nilendu \&

Madanmohan, 2002) and the strategic motivations for companies to release open

source code (Lerner \& Tirole, 2002a). Research on what changes when large

companies release proprietary code to open source software projects is lacking.

\footnotetext{
1 AOL invested \$2 million to establish the Mozilla open source foundation (Niccolai, 2005). IBM releases its Eclipse code as open source, a contribution valued at $\$ 40$ million, and donated 500 of its software patents to open source software communities (Koenig, 2004; Galli, 2005). Sun released part of the code of the Solaris 10 operating system along with more than 1,600 patents under open source (Cover, 2005).
} 


\subsection{Objective}

The objective of this research is to answer the following six questions that pertain to when a large company releases its proprietary code as open source:

1. What changes occur to the players in the company's value net?

2. How does the company create and appropriate value?

3. What open source licenses does the company use?

4. What factors encourage or discourage developers and third parties to contribute to the open source project?

5. How does the company's revenue model change?

6. What are the main benefits and risks to the company that releases code to an open source project?

This research does not intend to measure the performance of the company that releases the code as open source. It examines the context the business operates before and after the code is released to answer the research questions listed above.

\subsection{Outcomes}

This research delivers three outcomes:

- Answers to six research questions

- Insights generated from using the PARTS framework (Brandenburger \& Nalebuff, 1996) to examine the release of proprietary code as open source

- Recommendations to top management teams of large companies considering the release of proprietary code to an open source project 


\subsection{Relevance}

This research is of interest to at least three groups. First, top management teams of large companies will be able to use the outcomes of this research to assess the strategic opportunity of code release and identify the ways they can change conditions for the purpose of favouring their companies in the marketplace.

Second, researchers in strategic management may be interested in how releasing code as open source can be used by companies to create and appropriate value.

Third, researchers in open source will be interested in the insights on one specific type of contribution to open source projects: code release and the application of a cooperative game theory perspective to generate these insights.

\subsection{Contribution}

This research contributes to the literature stream that examines the strategic motivations of firms for releasing proprietary code as open source.

This research makes at least five contributions. First, managers can use the insights gained from this research to identify the ways to: (i) increase the value their companies can appropriate and (ii) decrease the value that other companies can appropriate with the release of code as open source. 
Second, this research makes a contribution by highlighting that while the release of code as open source increases the use value of the code, companies need strong business models to realize the exchange value of the code.

Third, this research makes a contribution by identifying that the release of code as open source: (i) changes the company's business model from selling code to selling support, hardware and other commercial offerings; (ii) enhances the company's original business model; or (iii) extends the company's business model.

Fourth, this research identifies six risks associated with the company's release of code as open source that are not discussed in the literature: (i) risk that the company does not become a well established competitor; (ii) risk that external developers do not contribute to the project; (iii) risk that open source licenses hinder contributions; (iv) risk that the project becomes hard to manage as it grows; v) risk that the company is perceived to dominate the open source project to its own advantage; (vi) risk that open source offerings may lower the value of the company's commercial offerings; and (vi) risk that fails to build a profitable business model behind the released code.

Fifth, this research further supports two risks of releasing code as open source that have been identified in the literature: (i) risk that others may "fork" the code and capture the value; and (ii) risk that the company's business priorities may conflict with the objective of the open source community. 


\subsection{Organization}

The thesis is organized into six sections. The first section is the introduction. The second section reviews the literature and identifies the lessons learned from reviewing it. The third section describes the research method. The fourth section presents the results. The fifth section discusses the results. The sixth section provides conclusions, describes the limitations of the research, and identifies opportunities for future research. 


\section{LITERATURE REVIEW}

This chapter is organized into eight sections. Section 2.1 reviews the literature on the motives that companies have for releasing their code as open source. Section 2.2 reviews the literature on risks the company exposes itself to when releasing code as open source. Section 2.3 reviews the literature on open source licenses. Section 2.4 reviews the literature on open source business models. Section 2.5 reviews the literature on OSS. Section 2.6 reviews the literature on software. Section 2.7 reviews the literature on value creation and value appropriation. Section 2.8 presents the lessons learned from the literature review.

\subsection{Motives for releasing code as open source}

Table 1 lists the motives that companies have for releasing their code as open source identified in the literature reviewed. 
Table 1: Motives for releasing code as open source

\begin{tabular}{|l|l|}
\hline Motive & Reference \\
\hline $\begin{array}{l}\text { (1) Increase the demand for complementary } \\
\text { products }\end{array}$ & $\begin{array}{l}\text { Lerner \& Tirole, 2002a; Lerner \& Tirole, 2004; } \\
\text { Gabriel \& Goldman, 2005; Henkel, 2003; } \\
\text { Hawkins, 2004 }\end{array}$ \\
\hline (2) Set standard & $\begin{array}{l}\text { Gabriel \& Goldman, 2005; Henkel, 2003; Koenig, } \\
2004\end{array}$ \\
\hline (3) Weaken competitors & $\begin{array}{l}\text { Lerner \& Tirole, 2002a; Henkel, 2003; Koenig, } \\
2004\end{array}$ \\
\hline (4) Build better relations with customers & Gabriel \& Goldman, 2005; Henkel, 2003 \\
\hline (5) Benefit from external support & Gabriel \& Goldman, 2005; Henkel, 2003 \\
\hline (6) Nurture innovation & Gabriel \& Goldman, 2005 \\
\hline (7) Gain reputation & Henkel, 2003 \\
\hline $\begin{array}{l}\text { (8) Provide gifts that trigger gift economy } \\
\text { effect which ultimately encourages others to } \\
\text { work in areas important to the company }\end{array}$ & Gabriel \& Goldman, 2005 \\
\hline
\end{tabular}

\section{Increase the demand for complementary products}

Companies can benefit if they can offer products and services in proprietary segments of the market which complement the OSS (Lerner \& Tirole, 2004). Lerner and Tirole (2004) argue that code release is like giving away the razor (the released code) to sell more razor blades. The company that releases code as open source expects to boost its profit by selling products and services in complementary market segments. This strategy will make sense when the profit increase in the proprietary complementary segment offsets the profit decrease in the primary segment (Lerner \& Tirole, 2002a). 


\section{Set standard}

The release of code as open source develops network externalities that drive the establishment of a standard (Koenig, 2004). Some open source projects have as a goal the development of a standard such as API definitions, language extensions, or tool extensions. Releasing the code as open source increases the likelihood that what is proposed as the standard will be adopted (Gabriel \& Goldman, 2005).

\section{Weaken competitors}

Companies release code as open source to weaken competitors (Lerner \& Tirole, 2002a; Koenig, 2004). Releasing code as open source helps the company pursue new markets, position itself against established competitors more effectively (Koenig, 2004), and exert pricing pressure on competitors (Henkel, 2003). A company may also commoditize a particular layer of the software stack, eliminate competitors that are extracting revenue from that layer by releasing code as open source (Koenig, 2004).

\section{Build better relations with customers}

By releasing code as open source, commercial companies may generate good public relations with customers by inviting them to fix bugs and contribute enhancement (Henkel, 2003). Being included in the development process makes customers feel they are a part of the community working on the project. Giving customers access to the source code lets them assist in fixing the bugs and adding the features that they care most about (Gabriel \& Goldman, 2005). 


\section{Benefit from external support}

Companies release code as open source to receive design and development support from other firms and external developers or users (Gabriel \& Goldman, 2005; Henkel, 2003). An OSS project receives advice on the direction to pursue, new features and usability as well as help with implementation (Gabriel \& Goldman, 2005).

\section{Nurture innovation}

Companies release code as open source to find out what potential customers do with the code. This can lead to new products or new features for their existing products. By observing the problems other people are having, the company can innovate to solve or alleviate those problems (Gabriel \& Goldman, 2005).

\section{Gain reputation}

Companies release high quality OSS expecting to improve the company's technical reputation (Henkel, 2003).

\section{Trigger gift economy}

Gabriel and Goldman (2002) argue that by releasing the source code as open source, companies provide gifts that trigger a gift-economy effect. The products released, i.e., technology, tools, and prototypes are of high value to outside users or companies and encourage them to work in areas important to the company that releases the code. Companies providing this gift will benefit from the development triggered by the code release in which various factors, i.e. users, third parties, and the evolution of products will affect each other and drive the value creation process. 


\subsection{Risks the company exposes itself to when releasing code as open source}

While a company that releases code as open source may face greater risks, it has greater chances to reap benefits from the open source project than other contributors (Henkel, 2003).

Table 2 lists the risks that a company exposes itself when it releases code as open source which were identified in the literature.

Table 2: Risks the company exposes itself to when releasing code as open source

\begin{tabular}{|l|l|}
\hline Risk & Reference \\
\hline $\begin{array}{l}\text { Loss of revenue due to loss of intellectual } \\
\text { property rights }\end{array}$ & Gabriel \& Goldman, 2002; Hawkins, 2004 \\
\hline $\begin{array}{l}\text { Loss of advantage given that competitors can } \\
\text { use code }\end{array}$ & $\begin{array}{l}\text { Gabriel \& Goldman, 2002; Hawkins, 2004; } \\
\text { Henkel, 2003 }\end{array}$ \\
\hline $\begin{array}{l}\text { High costs of contributing to the open source } \\
\text { project and resolving conflicts between } \\
\text { differences in company's goals and } \\
\text { community's goals }\end{array}$ & Henkel, 2003; Lerner \& Tirole, 2004 \\
\hline $\begin{array}{l}\text { Part of the community branches out with the } \\
\text { software }\end{array}$ & Henkel, 2003; Lerner \& Tirole, 2004 \\
\hline
\end{tabular}

Losing the intellectual property (IP) rights to the code may result in lost revenue. Gabriel and Goldman (2002) argue that companies must understand and isolate the true proprietary value of the code to the company before releasing it as open source. Usually companies would only release what is outside their core value as open source. But if what is valuable to external developers and firms is too small, the company will have a hard time surviving as others crowd into its space (Gabriel \& Goldman, 2002). 
A company that releases its code may lose competitive advantages (Gabriel \& Goldman, 2002; Henkel, 2003). The company that releases code as open source must consider the potential benefits to competitors from accessing the code in addition to any revenue lost (Hawkins, 2004).

A company that releases its code as open source also faces two other risks: (i) high costs of contributing to the open source project and resolving conflicts between differences in company's goals and community's goals and (ii) possibility that part of the community forks out into a new independent community and evolves the code in a different way (Henkel, 2003; Lerner \& Tirole, 2004).

\subsection{Open source licenses}

The literature on open source licenses can be grouped into two streams: studies dealing with the description and classification of the features of open source licenses and studies on why companies choose a particular license (Bonaccorsi \& Rossi, 2005).

\subsubsection{Open source license types}

The Open Source Initiative (Open Source Initiative, 2005) has certified 58 licenses as open source licenses as of July 2006. Lerner and Tirole (2002b) categorize open source licenses into three groups according to the restrictiveness of the license: unrestrictive (e.g., BSD), restrictive (e.g., LGPL), and highly restrictive (e.g., GPL). They focus on two critical characteristics when classifying the license type. First, the license is termed as being "restrictive" if the license requires that when modified 
versions of the program are distributed, the source code must be made available. Such a provision is also referred to as a "copyleft" provision. Second, the license is deemed to be "highly restrictive" if the license restricts modified versions of the program from mingling their source code with other software that does not employ such a license. Such a clause is sometimes referred to as "reciprocal" or "viral".

The most popular used open source licenses are General Public License (GPL), Lesser GPL (LGPL) and a category combining Berkeley Software Distribution (BSD), MIT, Apache and Public Domain (Valimaki \& Oksanen, 2002).

\section{$\underline{\text { GPL }}$}

GPL is the most widely used open source license (Spiller \& Wichmann, 2002). Under the GPL, the user has to agree not to impose licensing restrictions on others and any distribution of modified versions of the program must make available all changes to the source under the same license. Furthermore, the recipient of such source inherits the full rights to use or redistribute the program and code in any manner desired (Stallman, 1996).

GPL forbids the derivative work to be released under a proprietary license. This enhances the diffusion of software under the GPL license and guards the incentives of developers because it assures them that the code will remain open forever (Bonaccorsi \& Rossi, 2005). However, the very strong "copyleft" makes GPL not very businessfriendly because a company would have to reveal their software source code if they used (in the sense of included) parts of GPL software to develop it (Spiller \& Wichmann, 2002). 
Additionally, to use code from another license, it must be assimilable by the viral license. Thus many other licenses are called "GPL incompatible", as they may not be re-licensed upon distribution with the GPL code.

\section{$\underline{\text { LGPL }}$}

Lesser GPL (LGPL) is a variant of the GPL license that promotes the use of GNU C libraries and Free Software libraries. A computer program can call a library released under the LGPL and maintain its own license scheme. The inheritance provision does not apply in this case (Bonaccorsi \& Rossi, 2005). LGPL allows greater flexibility regarding the "mixing" requirement. Programs are allowed to link with (or employ) other programs that are not themselves available under an open source license. In all other respects, however, the LGPL is similar to the GPL (Lerner \& Tirole, 2002b).

\section{$\underline{\text { BSD }}$}

BSD is the most permissive license. BSD allows anyone to freely copy and modify the source code, requiring only a notice of the original copyright in any redistribution in source or binary form. It is much less constraining than the GPL. BSD allows the redistribution of derivative works under any license scheme. Moreover, it is possible to prepare derivative works by mixing BSD and proprietary code. Users can modify the mixed program and redistribute it for a fee without making the source code freely available. Changes may be made to the source code by a firm that then keeps the changes private and charges for the resulting binaries. The BSD is more commercial friendly than GPL and LGPL (Schadler et al., 2003), but it paves the way for code hijacking and increases the risk of project forking (Bonaccorsi \& Rossi, 2005). 


\subsubsection{Choice of open source licenses}

The choice of an open source license may impact the benefits or welfare of the programmers and users as well as the opportunities of commercial software vendors and support providers (Lerner \& Tirole, 2002b; Hawkins, 2004).

Bonaccorsi and Rossi (2005) examine the license choice of 146 Italian firms that supply open source products and services. They argue that copyleft licenses play a dominant role. Only a small proportion of companies, however, adopt copyleft licenses within a pure model; $60 \%$ of firms combine copyleft with non-copyleft licenses. The use of mixed licensing models implies that firms know how to distinguish the legal implications of different licensing schemes.

Lerner and Tirole (2002b) examine the relationship between license choice and project characteristics. They argue that projects that target end-users tend to have restrictive licenses, while those that target developers do not use restrictive licenses. Restrictive licenses are less common for projects designed to run on commercial operating systems and target the Internet. A more tentative conclusion is that projects that involve software developed in a corporate setting are likely to have more restrictive licenses (Lerner \& Tirole, 2002b).

\subsection{Open source business models}

The use of the right business model is a critical issue for all firms. Open source licenses allow the free redistribution of software, and the licenser doesn't necessarily 
generate revenue from selling copies of the software. Thus, there is a need for new business models that allow companies to generate revenue from open source (Nissila, 2004).

Although the concept of a business model is widely discussed in the management literature, there is little consensus on the definition of a business model. Morris et al. (2005) argue that in the most rudimentary level, a business model is just the firm's economic model concerned with the logic of profit generation. At the operational level, the business model describes the architectural configuration of the firm, the focus being on internal processes and design of value creation infrastructure. Finally, at a strategic level, the model represents the overall direction in the firm's market positioning, inter-organizational boundaries, and growth opportunities. At the strategic level the business model construct builds upon central ideas in business strategy and its associated theoretical traditions such as: value chain and value system concepts, resources-based theory, strategic network theory, cooperative strategies, and theories of firm boundaries and transaction costs.

According to Timmers (1998), a business model consists of: (i) an architecture for the product, service and information flows, including a description of the various business players and their roles; (ii) a description of the potential benefits for the various business players; and (iii) a description of the sources of revenue.

Chesbrough and Rosenbloom (2002) define a business model as a mediating construct between technology and economic value and identify six main functions of a business 
model: (i) value proposition; (ii) market segment; (iii) internal value chain; (iv) cost structure and profit potential; (v) value network; and (vi) competitive strategy.

Companies have found ways to incorporate OSS into their business (Koenig, 2004). Table 3 provides the several business models that rely on OSS identified by Hecker (1999). 
Table 3: Open source business models

\begin{tabular}{|c|c|}
\hline Name & Idea behind the model \\
\hline Support Sellers & $\begin{array}{l}\text { Revenue comes from media distribution, branding, training, consulting, } \\
\text { custom development, and post-sales support. }\end{array}$ \\
\hline Loss Leader & $\begin{array}{l}\text { A no-charge open source product is used as a loss leader for traditional } \\
\text { commercial software. }\end{array}$ \\
\hline Widget Frosting & $\begin{array}{l}\text { Companies in business primarily to sell hardware use the open source } \\
\text { model for enabling software such as driver and interface code. }\end{array}$ \\
\hline Accessorizing & $\begin{array}{l}\text { A company distributes books, computer hardware, and other physical } \\
\text { items associated with and supportive of OSS. }\end{array}$ \\
\hline Service Enabler & $\begin{array}{l}\text { OSS is created and distributed primarily to support access to revenue- } \\
\text { generating online services. }\end{array}$ \\
\hline Brand Licensing & $\begin{array}{l}\text { One company charges other companies for the right to use its brand } \\
\text { names and trademarks in creating derivative products. }\end{array}$ \\
\hline Sell It, Free It & $\begin{array}{l}\text { A company's software products start out their product life cycle as } \\
\text { traditional commercial products and then are continually converted to } \\
\text { open source products. }\end{array}$ \\
\hline Software Franchising & $\begin{array}{l}\text { This model combines several of the preceding ones in particular Brand } \\
\text { Licensing and Support Sellers. A company authorizes others to use its } \\
\text { brand names and trademarks in creating associated organizations doing } \\
\text { custom software development in particular geographic areas or vertical } \\
\text { markets. The company might also supply franchises with training and } \\
\text { related services in exchange for franchise fees of some sort. }\end{array}$ \\
\hline
\end{tabular}

(Source: Hecker, 1999)

Spiller and Wichmann (2002) identify several types of business models that would not exist without OSS. Figure 1 provides an overview of these business models. 
Figure 1: Open source business models

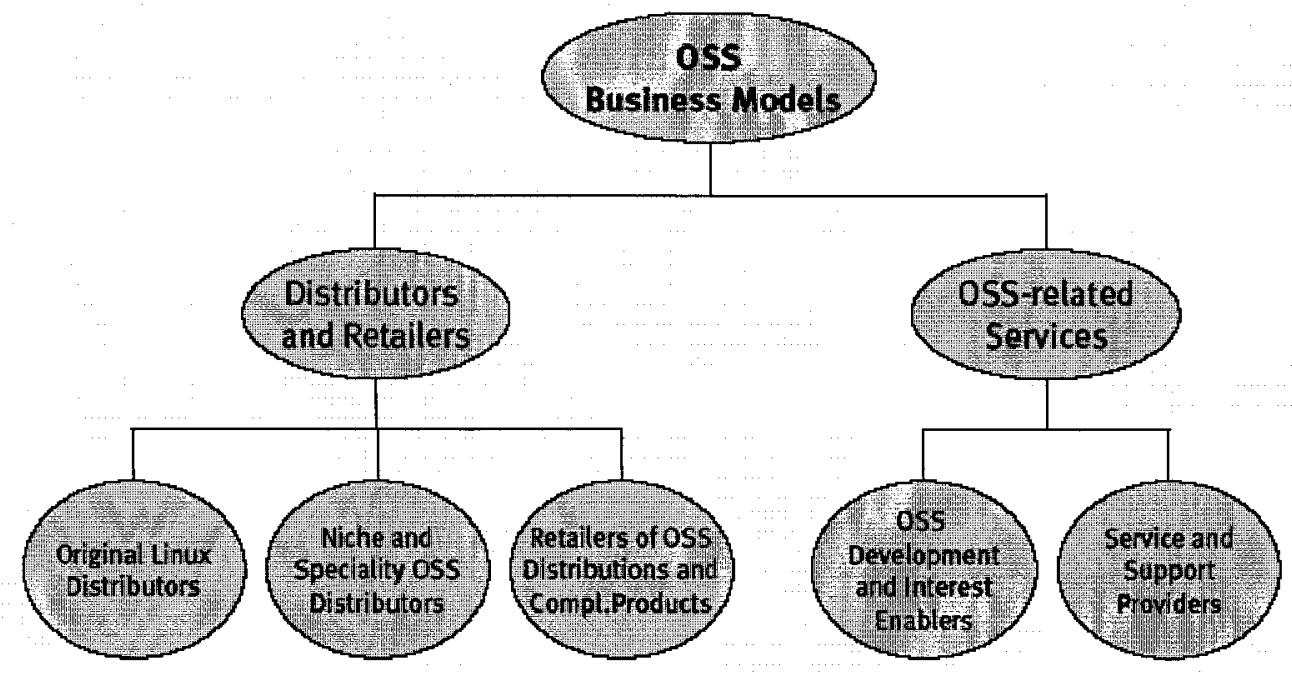

(Source: Spiller \& Wichmann, 2002)

The original Linux distributors package and sell their own versions of Linux. To endusers, these distributors sell Linux in various software packages and bundles. To IT administrators, they sell appropriate administration tools. To developers, they sell development tools. A critical success factor in Linux distribution is brand building.

The niche and specialty OSS distributors develop and distribute OSS other than operating systems. In this model, the company collects, maintains and develops OSS in a symbiotic relationship with the community. Typically, the major customers are Value Added Resellers (VARs) or Original Equipment Manufacturers (OEMs). 
Retailers of OSS distributions and complementary products sell software products or provide and sell additional documentation and information of OSS products. They do not develop OSS themselves, but focus on distribution and/or publishing.

OSS development and interest enablers are either marketplaces that match potential buyers and sellers, or conference organizers who provide opportunities for the OSS community and business partners to meet.

Service and support providers offer product or integration and service knowledge to customers.

Hawkins (2004) provides a revenue model for a software producer. The "revenue" is defined loosely so as to include both the firm producing for outside distribution and the firm producing for internal needs. Four major sources of revenue are included in the model: (i) direct sales of software; (ii) support contracts; (iii) increased hardware sales; and (iv) the value of internal use.

Nissila (2004) identifies three key elements of any software business model: (i) value creation and revenue logic; (ii) market offerings and positioning; and (iii) product development, implementation and servicing.

Hope (2003) distinguishes open source business models from standard business models in software and argues that compared to standard models that emphasise end value from selling the products, open source models emphasise generating use value 
by expanding the resources available to the company to include resource that lie outside the firm boundary.

\subsection{Research on open source software}

Open source strategies were born as reactions to proprietary strategies. They differ in terms of the openness and accessibility of intellectual property rights (Lecocq \& Demil, 2002). Proprietary strategies enable firms with patents and copyrights to control valuable technology or interfaces (Shapiro \& Varian, 1999). Firms prefer proprietary strategies because they provide better barriers to imitation and greater margins (West, 2003).

Open source strategies lie at the opposite end of proprietary strategies. The key concept of open source is that there should be unrestricted access to the source code. Anyone should be placed in the position to use and modify the code and distribute any modification without having to pay license fees (Open Source Initiative, 2005). Rather than using formal intellectual property right protection to set boundaries between vendors and their competitors and customers, open source enlists all as collaborators. Open source is designed to maximize adoption throughout the value chain and minimize the options for appropriating rents from the software (West, 2003).

Moczar (2005) organizes OSS development models into two types: the volunteer model and the commercial model. In the volunteer model, OSS is initiated by individual developers who have a personal goal or vision, then amplify it through the effective construction of voluntary communities of interest (Raymond, 1999). 
Typically, that original developer will begin working on the code either from scratch or by cannibalizing extant software (Raymond, 1999; Godfrey \& Tu, 2000). Linux is an example of the volunteer model of OSS.

Under the commercial model, organizations either start brand-new open source projects of their own or release formerly proprietary code as open source. Under the commercial model, companies create or sponsor open source projects seeking to incorporate the advantages of open source development into their businesses (Moczar, 2005).

\subsubsection{Motives for contributing to open source projects}

The motivations of individuals and firms to contribute to open source projects are different (Bonaccorsi \& Rossi, 2004). Individual developers are motivated by social and pragmatic factors (Hertel et al., 2003). Programmers contribute to the development of OSS to enhance their reputation among their peers (Raymond, 1999), learn and develop new skills, improve software for one's own use, solve important problems for themselves and others, share knowledge and skills, and derive pleasure from writing code (Hars \& Ou, 2002; Hertel et al., 2003; Hecker, 1999; Lakhani et al., 2002; Wichmann, 2002). These programmers hold a general belief that code should be open and feel an obligation to contribute back to the open source community (Hars $\& \mathrm{Ou}, 2002)$. Other authors also stress the factor of pragmatic career concern (Lerner $\&$ Tirole, 2002a). 
A programmer working on an OSS project incurs an opportunity cost of her time. A programmer who works on an open source project may be forgoing the monetary compensation she would receive if working for a commercial organization or risk delaying her primary work (Lerner \& Tirole, 2002a).

Rota et al. (2002) argue that the Internet makes it possible for a software developer to access a wide audience at very low costs. Moreover, the cost of providing answers to open source projects is very low (Lakhani \& von Hippel, 2003).

Table 4 identifies the motives of firms' participating in open source projects. 
Table 4: Motives of firms' participating in open source projects

\begin{tabular}{|c|c|}
\hline Motive & Literature \\
\hline $\begin{array}{l}\text { (1) Increase the demand for } \\
\text { complementary products }\end{array}$ & $\begin{array}{l}\text { Bonaccorsi \& Rossi, 2004; Hawkins, 2004; Henkel, 2003; } \\
\text { Lerner \& Tirole, 2002a; Lerner \& Tirole, 2004; von Hippel } \\
\text { \& von Krogh, } 2003\end{array}$ \\
\hline (2) Nurture innovation & $\begin{array}{l}\text { Bonaccorsi \& Rossi, 2004; Gabriel \& Goldman, 2005; } \\
\text { Raymond, 1999; von Hippel, 2002; von Hippel \& von } \\
\text { Krogh, } 2003\end{array}$ \\
\hline $\begin{array}{l}\text { (3) Use OSS as a low cost } \\
\text { component }\end{array}$ & $\begin{array}{l}\text { Bonaccorsi \& Rossi, 2004; Fink, 2003; Hawkins, 2004; } \\
\text { Wichmann, } 2002\end{array}$ \\
\hline (4) Set standard & $\begin{array}{l}\text { Gabriel \& Goldman, 2005; Koenig, 2004; Raymond, 1999; } \\
\text { Wichmann, } 2002\end{array}$ \\
\hline (5) Implement strategy & $\begin{array}{l}\text { Henkel, 2003; Koenig, 2004; Lerner \& Tirole, 2002a; } \\
\text { Wichmann, } 2002\end{array}$ \\
\hline (6) Benefit from external support & $\begin{array}{l}\text { Bonaccorsi \& Rossi, 2004; Gabriel \& Goldman, 2005; } \\
\text { Raymond, } 1999\end{array}$ \\
\hline $\begin{array}{l}\text { (7) Make money on complementary } \\
\text { services }\end{array}$ & Bonaccorsi \& Rossi, 2004; Wichmann, 2002 \\
\hline (8) Gain reputation & Henkel, 2003 \\
\hline
\end{tabular}

\section{Increase the demand for complementary products}

Firms participate in open source activities to generate revenues from the sale of related products (Henkel, 2003). For these firms, contributing to OSS makes sense because they need the OSS to complement their commercial offerings. 
For example, manufacturers such as Compaq, IBM, and Sun as well as distributors such as Red Hat, SuSE, and TurboLinux contribute to the GNOME project since they need the GNOME desktop customized to their requirements (Henkle, 2003). The GNOME desktop is a piece of software that runs on GNU/Linux and several other UNIX operating systems. It was developed as a reaction to the widespread criticism that GNU/Linux was not user-friendly.

\section{Nurture innovation}

The link between open source and innovation processes is widely debated in the literature (von Krogh et al., 2003). Although it has been pointed out that most open source programs are imitations of proprietary solutions, it has been argued that the free circulation of ideas provides an environment that fosters innovation (Raymond, 1999 ) and reduces the cost for small firms to carry out innovative work (Bonaccorsi \& Rossi, 2004).

Developers who are also users of the software make most of the contributions to OSS projects (von Hippel \& von Krogh, 2003). Open source development enables user innovation networks where users develop, produce, distribute and consume software. User innovation networks can function independently from manufacturers when: (i) users have sufficient incentive to innovate, and at least some users have an incentive to voluntarily reveal their innovations; (ii) diffusion of innovations is low cost and (iii) innovation can compete with commercial production and distribution (von Hippel, 2002).

\section{Use OSS as a low cost component}


An important reason for the increase in the use of OSS is its lower cost (Hawkins, 2004). Working with OSS enables firms to avoid license fees. Firms will use OSS if it is available at a low cost. Moreover, firms will participate in the production of commodity components of their product line as a method of reducing their development and maintenance costs (Wichmann, 2002; Hawkins, 2004).

Linux adoption is a good example of using OSS as a low cost component. Service providers see Linux as a way to deploy a system using commodity components and avoid paying license fees (Fink, 2003). When the operating system is not a differentiator, a firm that can produce bundles of hardware and software functionality to meet specific requirements at a low cost can gain competitive advantages (Wichmann, 2002). For many customers, the combination of relatively cheap Intel hardware and a free operating system fits their requirements better than an expensive albeit more powerful proprietary hardware and operating system combination (Wichmann, 2002).

\section{Set standard}

Setting a standard is another possible benefit pursued by commercial firms involved in open source projects. This is particularly important for infrastructure and tools (Raymond, 1999). Adopting open source models helps develop network externalities and imposes a standard in network industries (Lecocq \& Demil, 2002; Gabriel \& Goldman, 2005; Koenig, 2004).

Wichmann (2002) identifies the common interest in a single operating system as the main reason for hardware manufactures' involvement in Linux development. 


\section{Implement strategy}

Firms participate in OSS projects to weaken competitors or decrease dependencies on suppliers (Henkel, 2003; Wichmann, 2002; Lerner \& Tirole, 2002a; Koenig, 2004).

Companies may limit the code they release to that which provides non-essential functionality. For example, SAP released its SAP DB database, a software which is only needed to run the company's core ERP software (Wichmann, 2002).

\section{Benefit from external support}

Feedback and contributions from the open source community allow firms to lower software development and R\&D costs and improve their software through the bug fixing activities. Firms that release the source code of their programs to the open source community can exploit the R\&D activity undertaken by external developers to improve the code (Bonaccorsi \& Rossi, 2004). Given a large beta-tester and codeveloper base, almost every problem will be identified and solved quickly (Raymond, 1999).

Firms can obtain design or development support from external developers, improve the popularity and quality of the open source products, and build better relations with customers (Gabriel \& Goldman, 2005; Henkel, 2003). Ideas gathered from the open source projects may also be used to develop commercial solutions (Bonaccorsi \& Rossi, 2004).

\section{Make money on complementary services}


Software is getting more and more complex. This increases the demand for support services and paves the way for firms to make money on complementary services instead of selling software.

Under a proprietary framework, a firm that supplies services such as installation, integration, maintenance or support of proprietary programs pays license fees to the companies that own these programs. The open source framework does not allow fee payment on open source software. This enables firms to use business models that rely on the supply of software related services (Wichmann, 2002) and contribute to the trend of moving software from being a commodity market to a service market (Bonaccorsi \& Rossi, 2004).

\section{Gain reputation}

The need to appear as a "good citizen" in the open source community may be another reason for a firm to contribute to open source projects. If the software under consideration is of interest only to a small number of firms, then "being a good citizen" translates into reciprocity between these firms. In addition to building reputation as a good open source player, releasing high quality OSS will also improve the company's technical reputation (Henkel, 2003).

\subsubsection{Risks of open source development}

When compared with the studies that identify the benefits of OSS, studies on the risks of OSS, especially on risks of relying on open source projects are lacking. 
The working group on Libre Software (2000) identifies three main risks associated with open source development. First, there is no guarantee that development will reach a usable stage. Moreover, even if it reaches a usable stage, the project may die if there is not enough interest. Frequently this is the case when a project is started without strong backing from one or more companies.

The second risk of software development is due to intellectual property problems. It is very difficult to know if a particular method to solve a software problem is patented, and so the community can be considered guilty of intellectual property infringement.

The third risk of open source development is that sometimes it is difficult to know that a project exists, as well as its current status. Typically, open source communities do not advertise their software. This is particularly the case for those projects not directly backed by a company willing to invest in promotional campaigns for open source.

Yang (2005) identifies four risk categories that an OSS company faces when generating sales based on OSS projects: (i) OSS project dynamics; (ii) partners and support; (iii) competition; and (iv) development effectiveness.

For commercial companies that change from the proprietary to the open source development model, losing intellectual property rights may jeopardize company profits (Gabriel \& Goldman, 2002; Henkel, 2004). Competitors can also use the code released as open source, this may result in a loss of competitive advantage (Gabriel \& Goldman, 2002; Henkel, 2003). Conflicts between the sponsor's leadership and the 
objective of the open source community may arise during development (Henkel, 2003; Lerner \& Tirole, 2004). The firm that originates the software might lose control over its further development, even when it acts as the official maintainer of the respective public OSS project (Henkel, 2004).

\subsection{Research on software}

\subsubsection{Software taxonomy}

Software can be classified in several ways. Spiller and Wichmann (2002) provide the technical or functional classification for software shown in Figure 2. 
Figure 2: Technical and functional software product categories

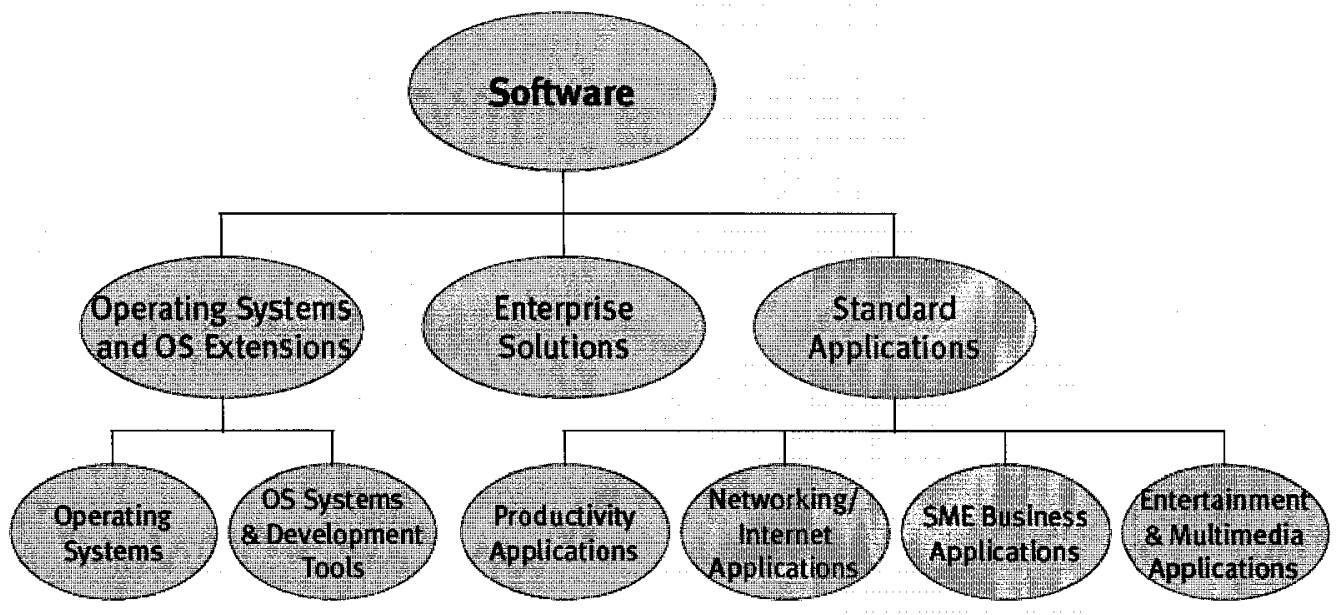

(Source: Spiller \& Wichmann, 2002)

Valimaki and Oksanen (2002) classify software by intended users: end-user software, developer software, and embedded software. Examples of end-user software are application and game software. For developer software, the value is in creating functionality. Modifiability and adaptability increase the value of developer software. Embedded software is for third parties who wish to implement the software as part of a larger product, either hardware or software. Compatibility is therefore necessary.

\subsubsection{Software value chain}

Spiller and Wichmann (2002) conceptualize software as being comprised of two parts: product and service. The product is the license that is sold to use the software. This license can be unique (customized software product) or it can be duplicated as many times as possible (standardized software product). Services include consulting, installation, implementation, support, training, and application management. 
Figure 3 shows the software value chain conceptualized by Spiller \& Wichmann (2002). According to this conceptualization, the software value chain includes product and service-related steps as well as marketing and distribution steps.

\section{Figure 3: Software value chain}

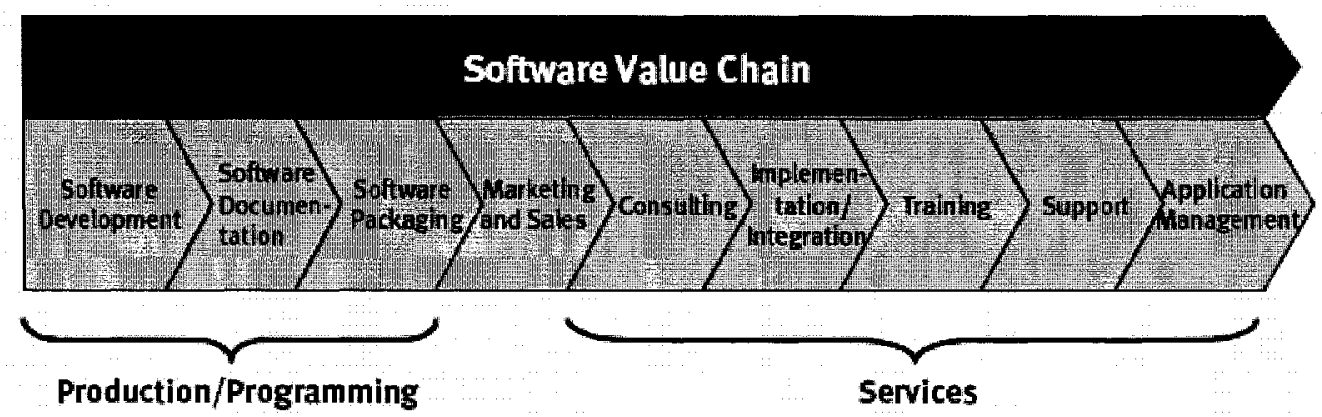

(Source: Spiller \& Wichmann, 2002)

The software value chain consists of three major parts: (i) production/programming;

(ii) marketing/sales (distribution); and (iii) services. Value is created in form of information about the products.

\subsection{Value creation and appropriation}

According to the resource-based theory, a resource is valuable if it exploits opportunities and/or neutralizes threats in a firm's environment (Barney, 1991). A valuable resource also enables customer needs to be better satisfied (Bogner et al., 1999). Economists tend to refer to utility theory and to the notion of marginal utility when examining value and consumer behavior (Bowman \& Ambrosini, 2000). 
To clarify the term "value", Bowman and Ambrosini (2000) distinguish between use value and exchange value. Use value refers to the specific qualities of the product perceived by customers in relation to their needs. It is subjective assessment made by customers based on their perceptions of the usefulness of the product offer. Exchange value is only realized at the point of sale which can be represented by the amount paid for the perceived use value.

Bowman and Ambrosini (2000) argue that use value is created by the actions of organizational members. Figure 4 shows the process of value creation.

\section{Figure 4: Process of value creation}

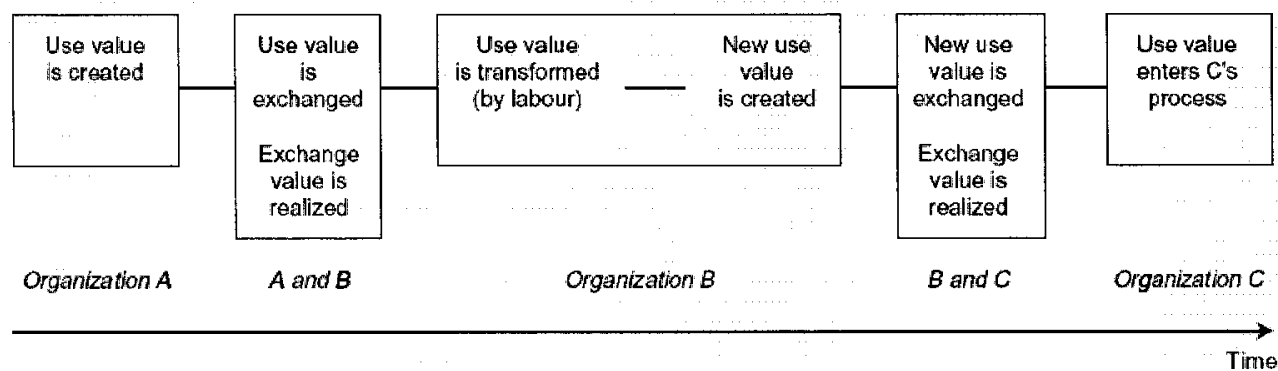

(Source: Bowman \& Ambrosini, 2000)

The use values of the other inputs into the production process are incapable of transforming themselves into new perceived use values. New use value is produced by combining acquired use values with labor. Exchange value is realized at the time of sale (Bowman \& Ambrosini, 2000).

Value can be created by trading or cooperating (Gans, 2005). In the supplier-firmbuyer trading context, value is defined based on a vertical chain extending from 
suppliers of resources to firms, and through firms to buyers of products and services from firms (Brandenburger \& Stuart, 1996). Value is created when a buyer's willingness-to-pay exceeds a supplier's opportunity cost. Value can also be created by co-operating. In this case, value is created by co-operation when a greater total value is created by engaging in the co-operative activity than by not engaging in it (Gans, 2005).

Agents that contribute to value creation activities are not guaranteed to appropriate value. For a company to make sustainable competitive advantage, it has to appropriate the value it creates. Brandenburger and Stuart (1996) propose an added value approach underpinned by cooperative game theory and the assumption that unrestricted bargaining defines the upper bound of how much value the firm can appropriate in the interaction with other players.

"Added value" is defined as a measure of a firm's contribution to the aggregate value created in market transaction activities. The added value of a player is defined as the difference between the value created by all players and the value created by all the players except the one in question (Brandenburger \& Stuart, 1996). Having a positive added value is a necessary condition for a firm to capture value (Brandenburger \& Stuart, 1996).

Added value can be used to assess a strategic opportunity and identify ways to change conditions to favour a company in its interaction with other agents. The approach enriches the applicability of economics to business thinking and reinforces economic principles in a business like environment (Gans, 2005). 
Brandenburger and Nalebuff (1996) argue that a company can change the dynamics of value creation and value appropriation in a business game by changing one of five elements: Players, Added value, Rules, Tactics, and Scope. These five elements are referred to as PARTS. Each element in PARTS is a powerful tool for transforming a game into a different one.

The value net describes all the various players and illustrates their relationships to each other (see Figure 5).

Figure 5: Value net

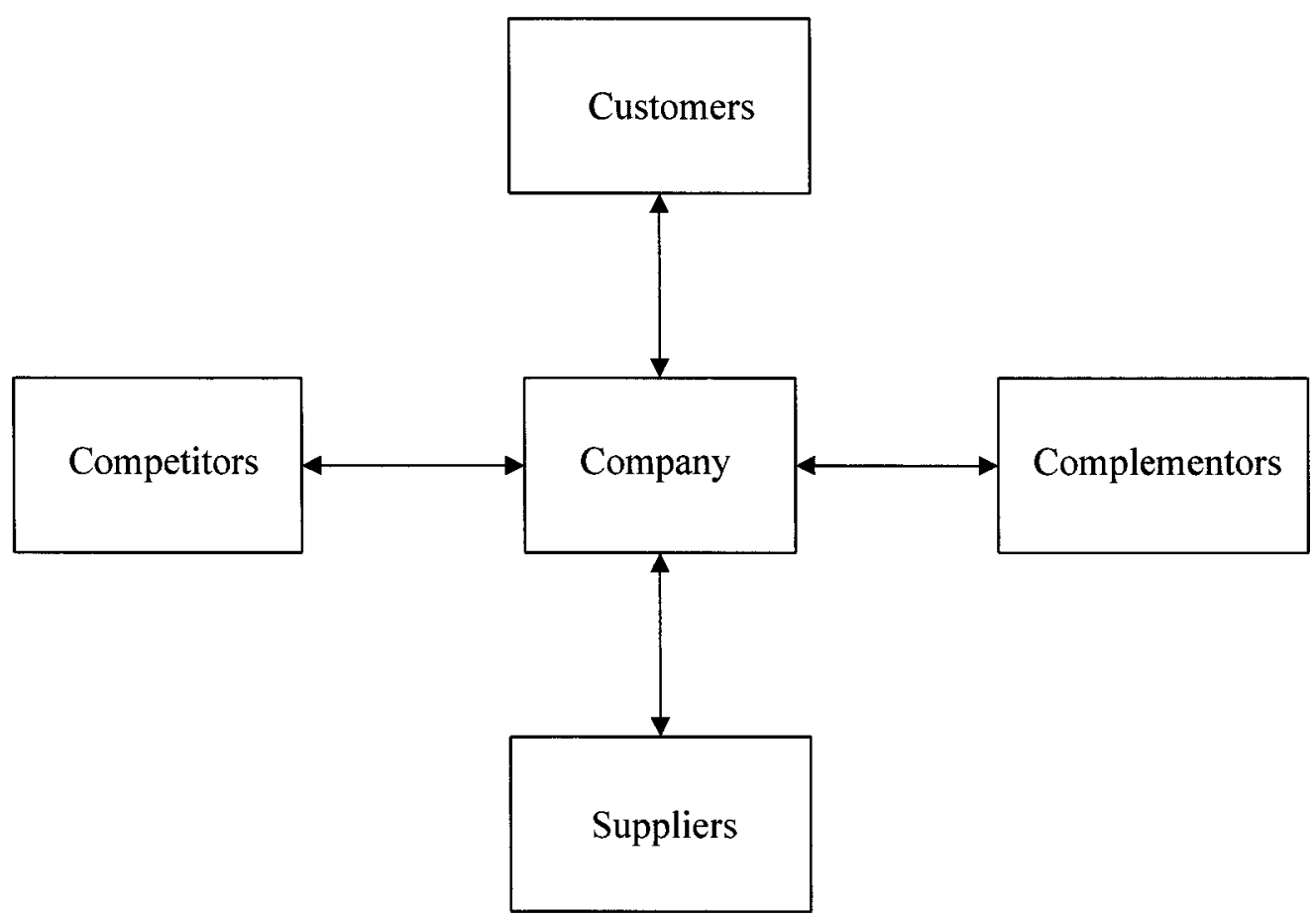

(Source: Brandenburger \& Nalebuff, 1996)

Along the vertical dimension, resources such as raw materials and labor flow from the suppliers to the company, and products and services flow from the company to the 
customers. Money flows in the reverse direction, customer to company and company to suppliers. Along the horizontal dimension are the company's competitors and complementors.

A complementor is a player who makes customers value the company's product more when they have the player's product than when they only have the company's product.

Companies can change the game to favor themselves by changing the cast of players, for example, by involving a greater number of complementors.

Added value determines who has power in a game and who will appropriate the larger payoffs. It is a measure of what each player contributes to the game and how much value the player can appropriate. By changing a game, a company can change its added value as well as the added value of other players. To capture more value, a company needs to increase its added value and limit other players' added value.

The rules structure the way the game is played. There is no universal set of rules, they can come from custom, contracts, or law. Adding or eliminating a rule can produce a big difference in the way a game is played out. A company can change the game to favor itself by changing the rules. The company can also impact other players' perceptions of the game by changing the rules.

Tactics are used to shape perceptions of other players. Other players' perceptions on the game affect their actions in the game. To adjust other players' behavior to favor 
the company, the company should figure out which perceptions it would like to preserve and which ones it would like to change.

Scope defines the links between the games in which the company is involved. The company has to pay attention to scope because the change of one game may influence the position of the company in another game.

\subsection{Lessons learned}

The following lessons were learned from the literature review:

1) There is a lack of research on how companies create and appropriate value when releasing code as open source. OSS as a part of corporate innovation strategies is still a comparatively recent phenomenon.

2) Value can be assessed from two aspects: use value and exchange value. Use value is represented by the quality, functions and other valuable features of the product perceived by customers and created by the actions of organizational members. Exchange value is represented by the amount paid by the buyer to the producer for the perceived use value and realized when the newly created use value is sold to customers who will compare the products with competing ones. There is a lack of research on how companies create use value and realize exchange value when releasing code as open source.

3) The literature on OSS business models focuses on business models used by pure open source companies. Companies that release code as open source may face 
very different situations when choosing suitable business models. Research on how companies adjust their business models to code release is lacking.

4) There is a lack of research on the risks of releasing code as open source.

5) Added value is a measure of how much the company contributes to the value creation process and how much value the company can appropriate. The added value method can be used to assess the ability of a firm to capture value from the interactions with other players.

6) The PART framework is a practical-oriented model designed to assess if a company can change a business game to favor itself. 


\section{RESEARCH METHOD}

This chapter is organized into three sections. Section 3.1 describes the unit of analysis. Section 3.2 describes the study period. Section 3.3 describes the research method.

\subsection{Unit of analysis}

The unit of analysis is the instance of a large company releasing its code as open source software.

\subsection{Study period}

The study period is from February 1998 to January 2006.

The start of the study period is marked by the first code release announcement made by Netscape in February 1998.

The end of the study period is marked by the month in which the researcher stopped collecting data.

\subsection{Research method}

The research method used in the thesis is comprised of six steps:

1. Set criteria for sample selection and select sample

2. Select theoretical perspective and define research questions

3. Collect data and build a database

4. Analyze data and create spreadsheets that capture changes in constructs 
5. Identify the company-related benefits and risks of releasing code as open source

6. Answer research questions, generate insights using the theoretical perspective selected and prepare recommendations for top management teams of large companies

\subsubsection{Set criteria for sample selection and select sample}

The criteria for sample selection was:

- The code was released after January 1, 1998 and before January 1, 2006

- The company that released the code was listed as a Fortune 500 company in 2005

- Required information for the company and the corresponding open source project was available on the Web

Only Fortune 500 companies were included in the sample because the purpose of the research was to examine the release of code to open source projects made by large companies. It was surmised that large companies faced different situations than open source start-ups. Open source start-ups are built around a pure open source business model while large companies are not.

A database that includes information on the companies that released code as open source does not exist. Thus, a database was built using information available online. This database included comprised seven fields: (i) company name; (ii) Web address of company's web site (i.e., Uniform Resource Locator or URL) (iii) name of the OSS 
project to which the code was released; (iv) year the code was released; (v) whether or not the company releasing the code was a Fortune 500 company in 2005; (vi) whether or not the required data was available on the Web; and (vii) whether or not the instance met the criteria to be included in the sample.

Online searches of Computerworld were performed to identify instances of code released as open source by large companies. The International Data Group (IDG) publishes Computerworld, an IT magazine that targets technology managers. It is published in many countries under the same or similar name. IDG publishes five publication product lines globally - Computerworld/InfoWorld, CIO, Macworld, Network World, and PC World. The searches conducted using the search engine available in Computerworld also covered information on the other magazines published by IDG.

The online search was performed using Computerworld search engine and the terms "open source" and "release". Search results were read and the instances in which a company released its code to one or more open source projects were identified.

\subsubsection{Select theoretical perspective and define research questions}

To examine the implications of code released to an open source project, the PARTS framework developed by Brandenburger and Nalebuff (1996) was used. The PARTS framework was selected because it helps to examine the whole game using five complementing perspectives that are relevant to companies and because it could be operationalized with the data available online. 
Building on the PARTS framework, six research questions were identified:

1. What changes occur to the players in the company's value net?

2. How does the company create and appropriate value?

3. What open source licenses does the company use?

4. What factors encourage or discourage developers and third parties to contribute to the open source project?

5. How does the company's revenue model change?

6. What are the main benefits and risks to the company that releases code to an open source project?

The first five research questions correspond to the five constructs of the PARTS framework. The first question corresponds to the Players construct, the second to the Added value construct, the third to the Rules construct, the fourth to the Tactics construct, and the fifth to the Scope construct.

\subsubsection{Collect data and build database}

For each instance that was included in the sample, the following information was collected: (i) company name; (ii) name of the OSS project to which the code was released; (iii) month and year the code was released; (iv) date in which the information was published; (v) hyperlink or reference that indicated the source of the data; (vi) open source license used; (vii) type of open source license used; (viii) intended users of the code; (ix) main motives the company had for releasing the code as open source; (x) company's offering(s) that generate revenue; (xi) information anchored around the five constructs defined in the PARTS framework; (xii) situation 
the company faced before releasing the code; (xiii) benefits and risks to the company releasing the code as open source; and (xiv) highlights of the information published.

A database was built to include the information collected. The database included the 14 fields identified above.

\section{Constructs of the PARTS framework}

Table 5 illustrates the five constructs of the PARTS framework and the key words that were employed to search for the information about the construct. 
Table 5: Constructs and key words

\begin{tabular}{|c|c|c|}
\hline Constructs & $\begin{array}{l}\text { Description of the construct in an open } \\
\text { source context }\end{array}$ & Key words used in searches \\
\hline Players & $\begin{array}{l}\text { Changes that occurred to players in the } \\
\text { company's value net }\end{array}$ & $\begin{array}{l}\text { Community, developer, partner, } \\
\text { supplier, customer, user, } \\
\text { competitor, vendor, cooperation, } \\
\text { download, market share, third- } \\
\text { party, membership }\end{array}$ \\
\hline Added value & $\begin{array}{l}\text { The added value of the company in the open } \\
\text { source project }\end{array}$ & $\begin{array}{l}\text { Market share, value, } \\
\text { contribution, quality, benefit, } \\
\text { technology, governance, } \\
\text { leadership }\end{array}$ \\
\hline Rules & The open source license used for the code & License \\
\hline Tactics & $\begin{array}{l}\text { The perceptions of other players about the } \\
\text { open source project }\end{array}$ & $\begin{array}{l}\text { Community, developer, partner, } \\
\text { competitor, vendor, contribute, } \\
\text { criticize }\end{array}$ \\
\hline Scope & $\begin{array}{l}\text { Changes that occurred to the company's } \\
\text { business model }\end{array}$ & $\begin{array}{l}\text { Business model, commercial } \\
\text { offering, complementary, } \\
\text { revenue }\end{array}$ \\
\hline
\end{tabular}

\section{Sources of data}

The information was collected using:

1. Google (www.google.com)

2. Computerworld (www.computerworld.com)

3. Infoworld (www.infoworld.com)

4. eWEEK (www.eweek.com ) 
The sources of data included: company websites, OSS project websites, company annual reports, company press releases, independent analysts' reports, and news releases.

\subsubsection{Analyze data and create spreadsheets that capture answers to research questions}

\section{Players}

The players' roles in the company's value net were identified as: suppliers, customers, competitors and complementors as described in Brandenburger and Nalebuff (1996).

For each instance of code release in the sample, the researcher first examined the information in the database and then identified the changes in players that occurred in the company's value net due to its release of the code as open source. These changes were organized into three types in a spreadsheet: (i) added new players (i.e., added new suppliers, customers, complementors) to the company's value net; (ii) changed the roles of the prior players (i.e.,made customers become suppliers, made complementors become suppliers, made competitors become suppliers, made competitors become complementors); or (iii) made the company a player in a monopoly like market.

\section{Added value}

Value added is a measure of what each player contributes to the game and how much value the player can appropriate. Building on Brandenburger and Stuart (1996), value 
added was operationalized to include two elements: the value created by all players (V), and the value created by players without the company $\left(\mathrm{V}_{-\mathrm{i}}\right)$.

For each instance of code release in the sample, the researcher identified how the company (i) increased the value of the code for its customers; (ii) reduced costs; and (iii) reduced or constrained the value added of other players. The actions undertaken to achieve goals (i) and (ii) were deemed to increase V, while the actions undertaken to achieve (iii) were deemed to decrease $\mathrm{V}_{-\mathrm{i}}$.

\section{Rules}

For each instance of code release in the sample, the researcher identified the type of open source license used.

Each license was classified into one of three categories: restrictive, highly restrictive and GPL compatible.

The open source license was deemed to be a restrictive license if it requires that the source code must be made generally available when modified versions of the program are distributed.

The open source license was deemed to be a highly restrictive license if it restricts modified versions of the program from mingling their source code with other software that does not employ such a license.

The open source license was deemed to be a GPL-compatible license if it allows the 
code developed under this license to be combined with code licensed under the GPL and the resulting work could be distributed without violating the terms of the GPL.

\section{Tactics}

For each instance of code release in the sample, the researcher identified the factors that encouraged or discouraged developers and third-parties to contribute to the open source project. The data that implied a positive effect on developers and third-parties' intentions to contribute was identified as factors that encouraged developers and thirdparties to contribute. The data that implied a negative effect on developers and thirdparties' intentions to contribute was identified as factors that discouraged developers and third-parties to contribute.

\section{Scope}

For each instance of code release included in the sample, the researcher identified how the code release affected the revenue model of the company. According to Hawkins (2004), the revenue models of companies' software products include: sales of proprietary software (R), sales of support services (S), increased sales of hardware that includes OSS $(\mathrm{H})$, and the value of internal use.

For each instance of code release in the sample, the researcher first examined the company's commercial offerings before and after the code was released and then identified changes in the company's revenue model. 


\subsubsection{Identify benefits and risks}

For each instance of code release in the sample, the researcher identified the benefits and risks of releasing code as open source.

\subsubsection{Answer research questions, generate insights and prepare recommendations for top management teams}

A set of insights was generated using the data and the literature.

Based on the insights, the researcher produced a set of recommendations to top management teams of large companies who are assessing releasing their code as open source. 


\section{RESULTS}

This chapter presents the results of the research. Section 4.1 identifies the six instances included in the sample and provides a brief description for each. Section 4.2 presents the changes of players in the company's value net that resulted from the release of the company's code as open source. Section 4.3 presents how the company increases its added value. Section 4.4 presents the open source licenses used by the companies that released code to open source projects. Section 4.5 presents the factors that encourage and discourage developers and third parties to contribute to the open source project to which the company's code was released. Section 4.6 presents the changes in the revenue model that occurred when the code was released as open source. Section 4.7 presents the company-related benefits and risks due to releasing code as open source.

\subsection{Sample}

Appendix A provides a list of instances of a company releasing its code as open source from January 1, 1998 to January 1, 2006. Appendix B describes the instances included in the sample.

Six instances of code release met the criteria for sample selection. The sample includes:

- Mozilla released by Netscape/AOL in 1998

- Darwin released by Apple in 1999

- Netbeans released by Sun in 2000

- OpenOffice.org released by Sun in 2000

- Eclipse released by IBM in 2001

- OpenSolaris released by Sun in 2005 
The other instances in Appendix A were eliminated because they did not meet one or more of the sample selection criteria stated in Section 3.4. For each instance of code released that was identified, Appendix A shows whether or not a specific criterion for sample selection was met.

Mozilla originated from the Netscape Navigator browser which dominated the market before Microsoft Internet Explorer was introduced in August 1995. Microsoft Internet Explorer gained more than $90 \%$ market share and quickly eclipsed Netscape Navigator. In January 1998, Netscape announced that its browser would be free and opened up its source code under an open source-style license. In November 1998, AOL (America Online) purchased Netscape and continued to provide support for the OSS Mozilla project.

The Eclipse open source project grew out of technology first developed by Object Technology International (OTI). OTI became a fully owned subsidiary of IBM located in Ottawa. Eclipse is used as a platform for integrated development environment (IDE). IBM open sourced the code for Eclipse in November 2001 with the backing of nine suppliers: Borland, WebGain, Red Hat, SUSE and others. IBM and the other suppliers formed a consortium to set up the open source project for the purpose of providing an extensible development platform and application frameworks for building software.

Sun's NetBeans platform originated as a student project that built an IDE using the Java programming language in the Czech Republic in 1996. In October 1999, Sun 
acquired NetBeans and combined the NetBeans platform with products and technologies from its acquisition of Forte Software Inc. and created its Forte for Java product. Sun gave Forte away for free and also released two commercial versions: (i) an Internet Edition for developing back-end software on a single Web server and (ii) an Enterprise Edition for deploying large, distributed Java applications. But while the Forte products were popular, they didn't exactly spread like wildfire. And it was costly to continually add all the features that developers were requesting. In June 2000, Sun released the NetBeans code as open source.

Sun acquired the StarOffice Suite from the German Star Division Company in 1999. StarOffice is a fully featured office suite that offers file and feature compatibility with most other mainstream office automation suites.

Problems with the features, loading times and response times of StarOffice were encountered. Sun decided in June 2000 to release the source code under an open source license to a project named OpenOffice.org. Future versions of StarOffice software have been built using the OpenOffice.org source, APIs, file formats, and reference implementation. Sun continues to sponsor the development of OpenOffice.org and it is the main code contributor.

OpenSolaris is based on a subset of the source code for the Solaris Operating System. In January 2005, Sun released OpenSolaris using a Common Development and Distribution License (CDDL). Sun also announced the release of 1,670 patents to the open source community. Initially, the OpenSolaris project provided the core kernel, libraries and commands that are currently distributed with the Solaris Operating 
System. Over time, it is expected that additional parts of the Solaris Operating System will be made available through the OSS project. The main difference between the OpenSolaris project and the Solaris Operating System is that the OpenSolaris project does not provide an end-user product or complete distribution. Instead it is an open source codebase and an infrastructure for communicating and sharing related information.

Darwin is the core of Mac OS X which is Apple's operating system software that runs on all Macintosh computers. In 1999, Apple released Darwin as open source. Darwin runs on PowerPC-based Macintosh computers and a version is also available for $\mathrm{x} 86$ compatible computers. To broaden the collaboration between Apple and the development community, OpenDarwin.org was founded in April 2002 by the Internet Software Consortium (ISC) with Apple's help. While the OSS project is fully independent, Apple continues to work closely with OpenDarwin for the purpose of bringing enhancements back into Mac OS X.

\subsection{Players}

Table 6 uses data in Appendix $C$ to illustrate the changes in players for the six cases in the sample. 
Table 6: Changes in players

\begin{tabular}{|l|l|}
\hline Changes in players & Instance \\
\hline Added customers & All \\
\hline Added suppliers & All \\
\hline Made customers become suppliers & All \\
\hline Added complementors & Mozilla, Netbeans, \\
\hline Made complementors become suppliers & OpenOffice.org, Eclipse \\
\hline Made competitors become suppliers & Mozilla, Netbeans, \\
\hline Made competitors become complementors & OpenOffice.org, Eclipse \\
\hline Company that released code became a player in a monopoly like & OpenOffice.org \\
\hline market & Netbeans, Eclipse \\
\hline
\end{tabular}

Table 6 shows that:

- In all instances that code was released as open source, the company: (i) added new customers; (ii) added suppliers; and (iii) made customers become suppliers.

- In four of six instances (Mozilla, Netbeans, OpenOffice.org and Eclipse), the code release added new complementors and made complementors become suppliers.

- In two cases (Netbeans and Eclipse), the code released made competitors become suppliers and complementors.

- In one case (OpenOffice.org), the company releasing the code was able to become a serious competitor in a monopoly like market dominated by another firm. 


\subsection{Added value}

Appendix D organizes the information collected into: (i) factors that increase the total value created (V) and (ii) factors that decreases the value that players other than the company can create $\left(\mathrm{V}_{-\mathrm{i}}\right)$. Appendix $\mathrm{D}$ further organizes $\mathrm{V}$ into: (i) factors that increase the customer value of the code and (ii) factors that decrease costs.

The information in Appendix D suggests that the factors that increase the customer value of the code include:

- Greater number of users

- Improved quality

- Increased functionality

- Greater number of applications built using the open source code

- Number of operating systems/hardware platforms supported increases

- Number of languages supported increases

- Open source code becomes the standard

The information in Appendix D suggests that the main factor that reduces costs is:

- Number of external individuals and third parties who develop the code without costing the company increases

The information in Appendix D suggests that to reduce or constrain the value that players can add the company that released the code should:

- remain the most important code and financial contributor to the open source project 
- influence the open source project to align the development of open source code with the company's goals

- use the open source license to exert greater power over the open source project relative to others

- release part of the code, not all of it

- release code that is specific to the company's hardware

- increase the market share of the products linked to the open source project

\subsection{Rules}

Table 7 identifies the open source licenses used by the open source projects in the sample.

Table 7: Types of open source licenses used by large companies when they release their code as open source

\begin{tabular}{|l|c|c|c|}
\hline & Restrictive & Highly restrictive & GPL-compatible \\
\hline $\begin{array}{l}\text { MPL/GPL/LGPL } \\
\text { (Mozilla) }\end{array}$ & $\mathrm{X}$ & & $\mathrm{X}$ \\
\hline $\begin{array}{l}\text { APSL } \\
\text { (Darwin) }\end{array}$ & $\mathrm{X}$ & & \\
\hline $\begin{array}{l}\text { SPL } \\
\text { (Netbeans) }\end{array}$ & $\mathrm{X}$ & & \\
\hline $\begin{array}{l}\text { SISSL(retired)/LGPL } \\
\text { (OpenOffice.org) }\end{array}$ & $\mathrm{X}$ & $\mathrm{X}$ \\
\hline $\begin{array}{l}\text { EPL } \\
\text { (Eclipse) }\end{array}$ & $\mathrm{X}$ & & \\
\hline $\begin{array}{l}\text { CDDL } \\
\text { (OpenSolaris) }\end{array}$ & $\mathrm{X}$ & & \\
\hline Count & $\mathbf{6}$ & $\mathbf{0}$ & $\mathbf{2}$ \\
\hline
\end{tabular}

Table 7 shows that all open source license used by the companies in the sample are restrictive. The license used can be divided into two groups: GPL-compatible and GPL-incompatible licenses. In the sample, Mozilla and OpenOffice.org use GPLcompatible licenses while the others do not. 


\subsection{Tactics}

Appendix $\mathrm{E}$ identifies the factors that encourage and discourage external developers and third parties to contribute to the open source project.

Appendix E suggests that the factors that encourage external developers and third parties to contribute to the open source project include:

- Use of a multiple license scheme that is GPL compatible

- Software development process is not controlled by one company

- Software development process is open and transparent

Appendix E also suggests that the factors that discourage external developers and third parties to contribute to the open source project include:

- Use of CDDL licenses that prohibit mixing code with Linux related code

- One company dominates the software development process

- Company that released the code as open source has unique rights over the code

- Code released is too complex, large or non-modular

- Code released is incomplete

\subsection{Scope}

For each instance, Appendix F shows how the large company generated its revenue before and after the code was released as open source. 
The data in Appendix F suggests that there are three types of changes in the company's revenue model that occur when the company releases its code as open source:

- Change from selling proprietary software and support to selling services such as installation, maintenance, and subscriptions

- Change from selling one proprietary offer to selling another proprietary offer based on the open source code released

- Change from providing free software to selling proprietary software based on open source and proprietary hardware with the proprietary software

For each instance of open source release included in the sample, Table 8 identifies the changes in the revenue model that occurred after the large company released its code to an open source project. 
Table 8: Change of revenue model

\begin{tabular}{|c|c|c|c|c|c|}
\hline Instance & $\begin{array}{l}\text { Market } \\
\text { offer } \\
\text { before } \\
\text { code } \\
\text { release }\end{array}$ & $\begin{array}{l}\text { Market } \\
\text { offer after } \\
\text { code release }\end{array}$ & $\begin{array}{c}\text { From } \\
\text { selling } \\
\text { proprieta } \\
\text { ry } \\
\text { software } \\
\text { and } \\
\text { support } \\
\text { to selling } \\
\text { services }\end{array}$ & $\begin{array}{l}\text { From } \\
\text { selling one } \\
\text { proprietary } \\
\text { offer to } \\
\text { selling } \\
\text { another } \\
\text { proprietary } \\
\text { offer based } \\
\text { on the open } \\
\text { source code } \\
\text { released }\end{array}$ & $\begin{array}{l}\text { From } \\
\text { providing } \\
\text { free } \\
\text { software to } \\
\text { selling } \\
\text { proprietary } \\
\text { software } \\
\text { based on } \\
\text { open } \\
\text { source and } \\
\text { proprietary } \\
\text { hardware } \\
\text { with the } \\
\text { proprietary } \\
\text { software }\end{array}$ \\
\hline $\begin{array}{l}\text { Mozilla, Netscape/ } \\
\text { AOL }\end{array}$ & $\begin{array}{l}\text { Proprietary } \\
\text { software } \\
\text { and } \\
\text { services }\end{array}$ & Services & $\bar{X}$ & & \\
\hline Darwin/Apple & $\begin{array}{l}\text { Proprietary } \\
\text { software, } \\
\text { services } \\
\text { and } \\
\text { hardware }\end{array}$ & $\begin{array}{l}\text { Proprietary } \\
\text { software, } \\
\text { services and } \\
\text { hardware } \\
\text { with a better } \\
\text { operating } \\
\text { system } \\
\end{array}$ & & $\mathrm{X}$ & \\
\hline Netbeans/Sun & $\begin{array}{l}\text { Proprietary } \\
\text { software, } \\
\text { services } \\
\text { and } \\
\text { hardware } \\
\end{array}$ & \begin{tabular}{|l|} 
Better \\
proprietary \\
software, \\
services and \\
hardware \\
\end{tabular} & & $\mathrm{X}$ & \\
\hline OpenOffice.org/Sun & Hardware & \begin{tabular}{|l|} 
Proprietary \\
software, \\
services and \\
hardware \\
\end{tabular} & & & $\mathrm{X}$ \\
\hline Eclipse/IBM & $\begin{array}{l}\text { Proprietary } \\
\text { software, } \\
\text { services } \\
\text { and } \\
\text { hardware } \\
\end{array}$ & $\begin{array}{l}\text { Better } \\
\text { proprietary } \\
\text { software, } \\
\text { services and } \\
\text { hardware }\end{array}$ & & $\mathrm{X}$ & \\
\hline OpenSolaris/Sun & $\begin{array}{l}\text { Proprietary } \\
\text { software } \\
\text { product }\end{array}$ & $\begin{array}{l}\text { Services and } \\
\text { hardware }\end{array}$ & $\mathrm{X}$ & & \\
\hline \multicolumn{3}{|l|}{ Count } & 2 & 3 & 1 \\
\hline
\end{tabular}


4.7 Benefits and risks

Appendix $\mathrm{G}$ identifies the company related benefits and risks of releasing code as open source. 


\section{DISCUSSION OF RESULTS}

This chapter is organized into three sections. Section 5.1 answers the six research questions. Section 5.2 describes the insights generated. Section 5.3 provides recommendations to top management teams of large companies considering the release of their proprietary code to an open source project.

\subsection{Answers to research questions}

The objective of this research was to answer the following six questions that pertain to when a large company releases its proprietary code as open source:

1. What changes occur to the players in the company's value net?

2. How does the company create and appropriate value?

3. What open source licenses does the company use?

4. What factors encourage or discourage developers and third parties to contribute to the open source project?

5. How does the company's revenue model change?

6. What are the main benefits and risks to the company that releases code to an open source project?

These research questions are answered in the subsections below. 


\subsubsection{Changes that occur to the players in the company's value net}

The research results suggest that three changes occur to the players in the company's value net:

- new customers, suppliers, and complementors are added to the company's value net

- the roles of players are broadened in the company's value net

- the company that releases code as open source becomes a player in a market dominated by a competitor

By releasing code as open source, a large company adds new customers, suppliers and complementors to its value net

Figure 6 uses data in Appendix $C$ to illustrate the new players that became part of the value nets of the companies in the sample after they released their code as open source. 
Figure 6: New players added to company's value net after code is released as open source

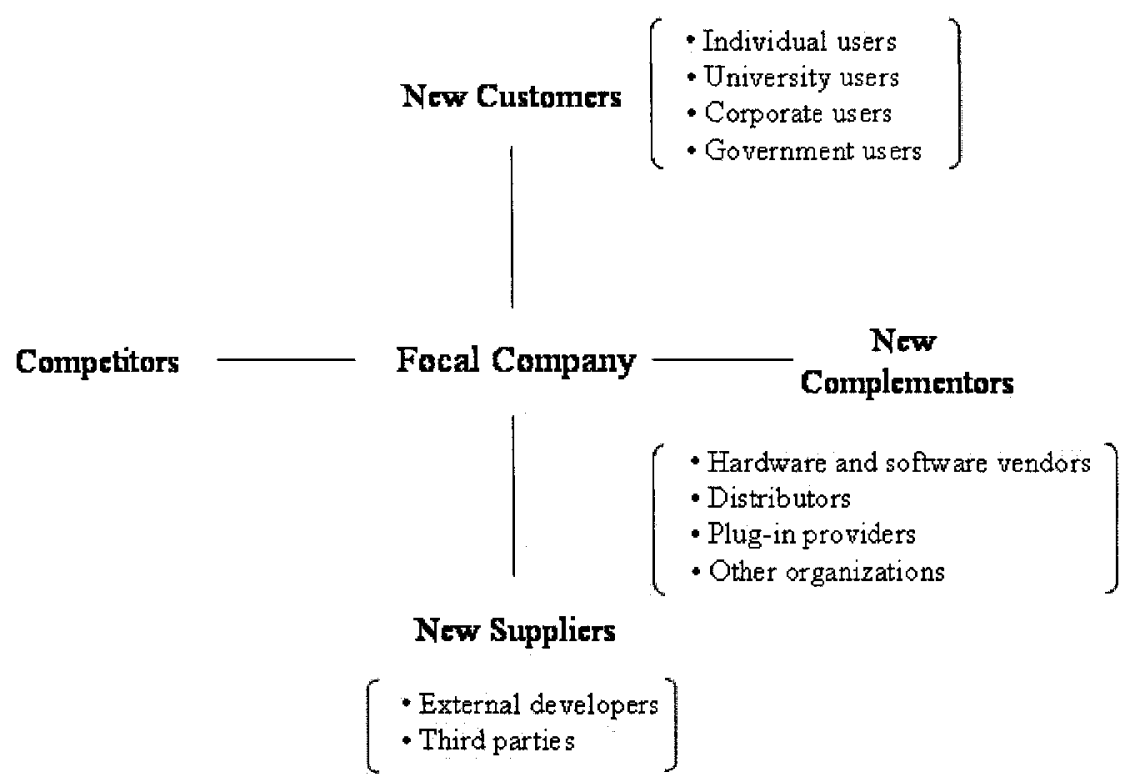

Figure 6 illustrates that the new players added to the large company's value net include new customers, suppliers and complementors. An organization can concurrently be a supplier, customer and complementor in the company's value net. For example, vendors like IBM, Sun and Red Hat are Mozilla's customers as well as suppliers and complementors. These companies are suppliers because they contribute developers and equipments to the Mozilla project. Moreover, they are also complementors because they incorporated Mozilla into their products. With complementors' products available, customers will value Mozilla's code more than just owning Mozilla's software.

Code release broadens the user base of the code. The six companies in the sample announced an increase in their user base after the code was released as open source. Among the new customers are individual users who download the software for personal use, corporate users who use the software in their business or incorporate the 
code with their own products, governments that seek to lower costs and value the freedom of the code, and universities that use the code for educational purposes.

A greater number of suppliers contribute to code development when the code is available as open source. For example, since its launch, Mozilla has attracted major UNIX system vendors including IBM, Sun, HP, and Red Hat interested in building businesses based on Mozilla. These vendors need a browser for their Internetconnected workstations. Thus, each of these UNIX systems vendors assigned software engineers to work with the Mozilla project to help keep the project moving forward and to ensure that new releases are compatible with their respective systems. Contributions from many organizations including Novell, Red Hat, Debian, Propylon, and Intel have ensured the ongoing presence and support for OpenOffice.org.

Eclipse was launched by IBM with 9 vendor backers. In 2004, this number had increased to 82 , and by the end of 2005 , Eclipse was backed by more than 100 vendors that built modules or plug-ins using Eclipse.

A greater number of third-party companies have become complementors of Netscape/AOL and Sun's products since the code for Mozilla and OpenOffice.org was released. Hardware and software vendors incorporate Mozilla-based browsers and OpenOffice.org with their products, Linux distributors sell their products bundled with Mozilla-based browsers and OpenOffice.org.

Eclipse has almost 30 strategic members who develop products based on Eclipse and more than 80 add-on providers who view Eclipse as an important part of their 
products and intend to add more features to Eclipse. Non-for-profit organizations, standards bodies, universities, research institutes and publishers also participate in the development of Eclipse. Companies like HP and Computerware distribute versions of Netbeans with additional functionality. More than 20 hardware and software vendors built applications on Netbeans. More than 40 plug-in providers built modules or plugins for Netbeans.

\section{By releasing code as open source, the large company broadens the roles of}

\section{players in its value net}

In all six instances of code release included in the sample, the company's customers also became suppliers and in four of the six instances the company's complementors also became suppliers.

The release of code as open source provides customers and complementors the opportunity and incentive to also become suppliers of code. Their role changes from just being customers or complementors to also being suppliers who make significant contributions to code development.

Complementors such as hardware and software vendors became suppliers by contributing developers and other resources to the open source projects. UNIX vendors such as IBM, Sun and HP are complementors for Netscape/AOL. Their products complement each other and customers would prefer to have a workstation with a browser installed than just owning one of the two. These complementors became contributors who assigned engineers and other resources to the Mozilla project. The same thing happened to Netbeans, Eclipse and OpenOffice.org. 
Companies that used to be complementors of the companies joined the open source projects to contribute.

Competitors became suppliers and complementors for Netbeans and Eclipse. Eclipse and Netbeans have gained the backing of key commercial tool vendors (i.e. BEA, Borland). These IDE vendors joined Eclipse and built commercial applications on Eclipse or Netbeans. Although the vendors are still competitors in IDE market, they became suppliers by contributing to the projects and complementors by developing new features and making the code more attractive to customers.

\section{By releasing code as open source, a large company may become a player in a market dominated by a competitor}

Code release strategy could be an efficient way for a company to get a foothold in a market with a firmly entrenched leader. For example, OpenOffice.org has become a major competitor to Microsoft's Office. Before being released as open source, Sun's StarOffice had little advantages and brand loyalty and it was far from perfect. The loading times and response times of OpenOffice.org have been improved over $200 \%$. OpenOffice.org is gaining market share from Microsoft's Office. Moreover, OpenOffice.org has become compliant with open standards where applicable. This is appealing to customers and third-party companies and has become a threat to proprietary standards.

Sun's release of StarOffice code changed the competitive landscape of the office suite market. The quality of the StarOffice code has improved and OpenOffice.org is 
gaining market share. OpenOffice.org and StarOffice have become serious competitors of Microsoft's Office.

\subsubsection{How the company creates and appropriates value}

To create new use value for the open source code, the company that released it garners external resource and players to:

- Improve the code to increase its value

- Reduce the cost of developing and maintaining the code

To increase the portion of the value that the company appropriates, the company must limit the value that other players, particularly competitors, can add to the value net anchored around the code.

Increase total use value (V) by concurrently improving the value of the code for customers and lowering the cost of developing and maintaining it Releasing code as open source provides opportunities to add value by concurrently improving the code and lowering development and maintenance costs at the same time.

Customers attach greater value to the source code when it is open than when it is closed because of the increased user base, improved quality and functionality, and the grater number of plug-ins and extensions built by third parties. For example, Eclipse has become a dominant design for Java IDE. Mozilla and OpenOffice.org have been developed to support multi-platform and multi-languages. Netbeans has attracted 
more than 60 third-party firms to build extensions or applications on Netbeans codebase. Eclipse has more than 80 providers of plug-ins. Darwin is designed to support both PowerPC and Intel microprocessor and Apple announced that the applications built on Darwin had doubled to more than 6,000 during 2002 .

The company's cost to develop and maintain the software is decreased when external developers contribute to the development and maintenance of the code. All companies in the sample benefited from contributions from external developers since they released code as open source. Companies have garnered resources such as developers and equipment from other firms or organizations.

\section{Large companies that release code as open source use five methods to limit the} value that other players can create

To increase the portion of the value that a company can appropriate, the company must limit the value other players can add to the code. Information in Appendix D suggests that a company that releases code as open source can limit the value other players can add in the following five ways:

- the company remains the most important code and financial contributor to the open source project

- the company's employees influence the open source project to maintain alignment with the company's goals

- the company uses the open source license to exert greater power over the open source project relative to others

- the company only releases part of the code

- the company releases code that is specific to the company's hardware 
To limit the value others can add, the company must bring more than others to the open source project. All the companies in the sample that released code remain the largest contributor for the open source projects. Mozilla's first license NPL granted Netscape additional rights over the code. Most module owners in Mozilla are Netscape/AOL employees. The Eclipse community has a tiered membership structure and a board of directors made up of a relatively small number of "strategic members" who are often responsible for leading important Eclipse projects. IBM remains to be a strategic member and hold a seat in the Eclipse board. The Netbeans Board consists of three members and one of them is always appointed by Sun. Two of the nine council members of OpenOffice.org are always Sun employees. One of the three members of OpenDarwin's core team is an Apple employee. Sun released only part features in Solaris and Darwin is the core of Mac OS X without the popular Macintosh graphical user interface and will not run Mac applications. Furthermore, particular code, such as Apple's Darwin, is favoured for use in Apple's hardware.

Contributing code, money, and people to the open source community enables the company to remain actively involved in the open source project and hold an important position in the open source community when determining the direction of the development. Companies also develop open source licenses to guarantee their rights on the code. Sun and Apple released part code of their operating system to keep others from capturing the core value of code. Darwin is specific to Apple's hardware, this limits other companies' opportunities of adding value. 
Devaluing the product of competitors is one of the important motives to release code as open source. The strategy works in this way because the market of the competitors' products will be attacked by the OSS offerings and company's commercial offerings at the same time. The OSS offerings provide low-cost substitutes for the competitors' products to low-end customers who value the low cost and the free right on the code. The commercial offerings provide value-added substitutes for the competitors' products to high-end customers who value the differentiating part built on the open source code.

\subsubsection{Open source license used}

\section{A large company is more likely to develop its own open source license when releasing its code as open source.}

Companies that release code may choose an existing open source license or develop a new one to meet their special objectives. While GPL and BSD are the most popular licenses used by open source projects (Valimaki \& Oksanen, 2002), in all six instances in the sample, companies released the source code under a license developed by the company or a dual-license scheme. None of the commercial company in the sample chose an all restrictive license (e.g. GPL) or an all permissive license (e.g. BSD).

All restrictive license (e.g. GPL) promotes constant growth of the code but limits the freedom of commercial developers. The more permissive BSD license only requires that the copyright holder be referenced in unlimited changes to code. However, companies did not use the BSD license when releasing their code as open source. 
Company-specific licenses aim to balance the interests of the open source development community as well as commercial programmers. They require modifications to be given back so that the entire community benefits and also encourage commercial usage of the code by allowing mixing the code with non-free software. These licenses tend to be strong in keeping the code and community together and be commercial-friendly at the same time.

\subsubsection{Factors that encourage and discourage external developers and third parties to contribute to the open source project}

Appendix E suggests that the factors that encourage external developers and third parties to contribute to the open source project include:

- Use of a multiple license scheme that is GPL compatible

- Software development process is not controlled by one company

- Software development process is open and transparent

Appendix E also suggests that the factors that discourage external developers and third parties to contribute to the open source project include:

- Use of CDDL licenses that prohibit mixing code with Linux related code

- One company dominates the software development process

- Company that released the code as open source has unique rights over the code

- Code released is too complex, large or non-modular

- Code released is incomplete 


\subsubsection{Changes to the company's revenue model}

Information in Appendix F suggests that there are three types of changes in the company's revenue model that occur when the company releases its code as open source:

- Change from selling proprietary software and support to selling services such as installation, maintenance, and subscriptions

- Change from selling one proprietary offer to selling another proprietary offer based on the open source code released

- Change from providing free software to selling proprietary software based on open source and proprietary hardware with the proprietary software

\section{From selling proprietary software and support to selling services}

When Netscape and Sun released Mozilla and OpenSolaris they gave up generating revenue from selling proprietary code. After the code was released as open source they generated revenue by selling services.

Before releasing Mozilla, Netscape generated revenue through the sales and support of Internet client and server software. After the Mozilla code was released, Netscape generated revenue from support contracts, and subscription/advertising revenue associated with portal sites.

Before releasing Solaris, Sun generated revenue through the sales of the proprietary Solaris operating system, a packaged software product. After the Solaris code was released, Sun generated its revenue through support and services. 
From selling one proprietary offer to selling another proprietary offer based on the open source code released

IBM's release of Eclipse, Sun's release of Netbeans, and Apple's release of Darwin did not change their revenue models. In all three instances the release of open source helped the sale of a proprietary offer built on the open source software.

IBM and Sun sold proprietary software before they released their code as open source. After the code releases, the companies sold proprietary software built on the open source software. Eclipse and Netbeans were proprietary commercial IDEs from which IBM and Sun generated revenue from product sales and support. Although releasing Eclipse and Netbeans made the code available to anyone, IBM sold its WebSphere studio tools based on Eclipse and Sun sold its Sun Java studio tools based on Netbeans. IBM and Sun also expected increased sales of hardware installed with software that included the code from Eclipse and Netbeans.

Darwin is the core of Mac OS X, the operating system of Apple's hardware. Apple's revenue model relies on the sales of personal computers and related software and services. The release of Darwin to an open source project did not change the nature of Apple's business model. Apple continues to sell personal computers. The release of Darwin as open source software improved the functionality of the software. Although Mac OS X generates little revenue on its own, the improvements Darwin made to the Mac OS X made Apple's personal computers more marketable. 
From providing free software to selling proprietary software based on open source and proprietary hardware with the proprietary software

Sun allowed users to download StarOffice for free from the company's website. Thus, StarOffice did not generate revenue for Sun before it was released as open source. After releasing the code as open source, Sun used the codebase as the core for a commercial StarOffice product. Sun sells StarOffice and servers installed with StarOffice mainly to independent software vendors and other corporations.

\subsubsection{Benefits and risks of releasing code as open source}

Appendix G suggests that the benefits identified with large companies releasing their code as open source include:

- Number of companies that contribute to code development increases

- Number of talented developers that contribute to code development increases

- Competitors join the open source project and contribute to code development

- Company was able to compete with a company that dominated the market

- Company can lower the market share of its competitors' products

- Company can influence the development of software by the open source community

Appendix $\mathrm{G}$ suggests that the risks identified with large companies releasing their code as open source include:

- External developers do not contribute to the open source project because they perceive the code released as open source as being too complex and do not 
perceive decision making and the software development process as being open and transparent

- Suppliers of proprietary software make their market offers more attractive for customers

- Open source software constrains or decreases sales of company's commercial offers

- Conflicts arise due to differences in the priorities of the company and the priorities of the open source community

- External developers perceive the company as manipulating the open source projects to gain competitive advantages in the marketplace

- Number of users of the open source software increases at a much faster rate than the number of developers does

- Another community forks the code

- Open source project becomes too big and difficult to manage

- Open source license used is not the right one

- Business model selected is not strong enough to generate profits for the company 


\subsection{Insights generated}

The following insights were generated from examining the results of the research within the context of the literature:

1. The release of incomplete code does not attract complementors

2. By releasing a development tool as open source, a large company makes competitors become suppliers and complementors

3. There are three types of positive consequences associated with the release of code as open source

4. Large companies that face difficult market situations are more likely to release code as open source than companies who are performing well

5. License choice is related to the type of software. Application software tends to have GPL-compatible license scheme while operating systems and development tools code do not

6. The greater the control of the large company over the open source code, the lower the external contributions to code development

7. Codebase complexity decreases external contributions to code development

8. The release of development platforms and tools as open source increases third party contributions to code development

9. Use of GPL-compatible licenses increases external contributions to code development while the use of GPL-incompatible licenses decreases these contributions 
The release of incomplete code does not attract complementors

Appendix C shows that no complementors were found for Darwin and OpenSolaris. The following three reasons may explain this result: first, both Darwin and OpenSolaris are only part of the original code. Although the open source Darwin is comprised of several of the core components of Mac OS X, it does not include the popular Macintosh graphical user interface and will not run Mac applications. Sun has released only part features in Solaris and limited the use of more than 1,600 Solarisrelated patents to software under CDDL. While Apple and Sun intend to keep the core value of the code, the incomplete code also limits the usability of the code by third parties. Second, Darwin is specific for Apple's hardware, which restricts the opportunity for third parties to capture value from it. Third, OpenSolaris was released in January 2005, and the researcher stopped collecting data in January 2006, it may take OpenSolaris longer to build complementary relationships with third parties.

\section{By releasing a development tool as open source, a large company makes competitors become suppliers and complementors}

Results shown in Appendix $\mathrm{C}$ suggest that releasing code for development tools as open source is more attractive to complementors. The open source code provides complementors with a common platform to cost-effectively build products on. Eclipse and Netbeans have attracted competitors to contribute to the open source projects and build products that complement the released code. IDE vendors such as Borland and BEA were IBM competitors. After the code was released, they became complementors and supplied code to the Eclipse project. For firms like Borland and BEA, contributing to the open source projects makes sense because Eclipse or 
Netbeans has offered a platform for these companies to cost-effectively develop their commercial products on a common codebase and benefit from the network externalities and economics of scope.

\section{There are three types of positive consequences associated with the release of code} as open source

Each member of the group recognizes and values its membership in the group, which generates three broad types of positive consequences: coordination effects, efficiency effects, and reputation effects (Peteraf \& Shanley, 1997).

\section{Coordination effects}

Coordination action around the open source projects stems from the recognition of mutual interdependence and potential benefits from cooperation. The coordination in a corporate open source project happens not only among individual developers but also among companies. It may increase the market power or enhance bargaining position of the strategic group as a whole. Mozilla-based browsers and OpenOffice.org have made significant gains since the release of code in terms of market share. Eclipse and Netbeans both see significant improvement in terms of number of partners and market share in the IDE market. Compared to Netbeans, Eclipse more explicitly and consciously fosters commercial adoption of its technologies, and works towards creating a commercially profitable ecosystem by providing an extensible architecture and flexible licensing model. The adoption of Eclipse increased more than 90 percent from 2003 to 2004 . Eclipse has become the most popular Java IDE in North America and is gaining ground on more established products. 


\section{Efficiency effects}

Players in an open source community tend to share information more readily. This decreases the cost of development and increases efficiency. Economies of scope occur when each contributor's overall development effort is reduced by cooperation with each other.

\section{Reputation effects}

The open source project with a strong identify is likely to be recognized by outside observers. Customers will recognize the strong identities of open source projects which will reduce their information search costs thereby increasing the relative value proposition offered by the group firms.

\section{Large companies that face difficult market situations are more likely to release code as open source than companies who are performing well}

The companies examine faced three situations before releasing their code as open source. First, the product was new to the company and the market was dominated by single competitor. This was the situation Sun's StarOffice encountered before it was released as OpenOffice.org. The market of office productivity software was dominated by Microsoft who had a massive marketing budget to promote its products worldwide. It was difficult for Sun's StarOffice to gain market share from the dominant competitor.

Second, the product used to have a high value in the marketplace, but it was facing keen competition and losing market share to strong competitors. This was the 
situation faced by Netscape's browser and Sun's Solaris before they were released. Netscape's browser and Sun's Solaris were losing marketplace to Microsoft's IE and Linux operating system respectively.

Third, the product needed more features to be attractive to users and it would be costly for the company to do the entire job by itself. This was the situation faced by IBM's Eclipse, Sun's Netbeans and Apple's Darwin.

\section{License choice is related to the type of software. Application software tends to have GPL-compatible license scheme while operating systems and development tools code do not}

MPL is a GPL-incompatible license, "incompatibility" in this context means that developers who combine code licensed under MPL with code licensed under the GPL and distribute the resulting work could not do such distribution without violating the terms of the GPL. Given that the LGPL contains similar language to the GPL, if the MPL were in fact incompatible in this way with the GPL, it would arguably be incompatible with the LGPL. To address the perceived license incompatibilities, Mozilla relicensed its code using an MPL/GPL/LGPL triple license. Dual- or triplelicense model allows the licensees who modify and/or distribute the code to choose which of the available sets of license terms they are operating under. Sun announced the retirement of the Sun Industry Standard Source License (SISSL) in September 2005 and began to use single LGPL scheme.

GPL-compatible license scheme addresses the concerns of developers who wish to use the code in applications whose code is otherwise licensed under the GPL or LGPL 
and thus may be more attractive to external developers.

Lerner and Tirole (2002b) suggest that permissive licenses will be more common in cases where projects have strong appeal to the community of open source contributors, and restrictive ones are commonplace when the appeal is more fragile. They also suggest that projects geared towards developers may be more likely to fall into the former category, while those geared towards individual end users are more likely to fall into the latter.

A project with a fragile community appeal has difficulties to attract developers because the ego gratification and career concerns incentives do not have much power and the benefits from tailoring the code for particular applications are weak. By way of contrast, code aimed at developers, and to a lesser extent, system administrators, is more likely to belong to the "strong community appeal" category (Lerner \& Tirole, 2002b).

Software like Mozilla-based browser and OpenOffice.org are applications geared toward end-users. Compared to other projects which are oriented to software developers (i.e., Eclipse and Netbeans) and system administrators (i.e., OpenSolaris), end-user oriented software has weaker community appeal compared to developer oriented or system administrator oriented software (Lerner \& Tirole, 2002b). Therefore, adopting a GPL-compatible license scheme makes sense because GPL is preferred by individual developers (Kasper, 2001). Darwin does not use a GPLcompatible license even though it also intends for end-users. Darwin is the core of Mac OS X and unlike application software that is designed for common end-users, 
Darwin is specific for Apple's hardware and may has strong community appeal to particular group of professional UNIX users.

Research results suggest that end-user oriented applications tends to adopt GPLcompatible license scheme, while operating system and development tools do not. This can be explained using the model developed by Lerner and Tirole (2002b). For projects with fragile community appeal, the licensor must opt for the compatible license scheme to obtain more participation. For project with strong community appeal, the licensor can choose the license scheme in a less unconstrained fashion.

\section{The greater the control of the large company over the open source code, the}

\section{lower the external contributions to code development}

The research results in Section 4.5 show that the greater power exerted by the company on the code results in the lower outside support for the code. For individual developers, personal fulfillment or gratification motivates them to contribute to an open source project. Developers contribute to an open source project to gain reputation among peers, learn and develop new skills, improve software for one's own use, solve important problems for them and for others, share knowledge and skills, and get pleasure from writing code (Raymond, 1999; Hars \& Ou 2002; Hertel et al., 2003; Hecker, 1999; Lakhani et al., 2002; Wichmann, 2002). It will be difficult for them to satisfy their social and pragmatic private needs if the development process is not open enough.

Third parties participate in the open source project to use OSS as a low-cost component or benefit from providing complementary services or products 
(Bonaccorsi \& Rossi, 2004; Fink, 2003; Hawkins, 2004; Wichmann, 2002; Henkel, 2003; Lerner \& Tirole, 2002a; Lerner \& Tirole, 2004; von Hippel \& von Krogh, 2003). These companies would not deeply involve in the projects if they perceive that the company still controls the project to its favor and there is very limit space for them to capture value from the projects.

\section{Codebase complexity decreases external contributions to code development} Mozilla and OpenOffice.org were perceived to have a very steep learning curve by potential developers in terms of number of lines and number of source files when they were released. It takes time for external developers to become comfortable and then competent of doing development since any developer outside the company has to start from scratch in terms of learning curve. Raymond (1999) emphasizes the importance of a reusable codebase when making it available to external developers. External developers will have trouble to contribute if the codebase is too large or complex for them to understand.

\section{The release of development platforms and tools as open source increases third party contributions to code development}

The research results in Section 4.5 show that development tools such as Eclipse and Netbeans attracted more third-party complementors than other open source projects did. Third-party companies participate in open source projects to profit on complementary products or services, afford innovation, share cost and promote standardization (Bonaccorsi \& Ross, 2004). Compared with application software, development tools are more extensible in terms on adding on other software. By pooling the industry's resources into a common set of extensible tools, each 
individual contributor's overall development effort is significantly reduced. Besides, end-user applications are hard to write, not only because a programmer has to deal with a graphical, windowed environment which is constantly changing, nonstandard, and buggy simply because of its complexity, but also because most programmers are not good graphical interface designers, with notable exceptions (Behlendorf, 1999).

\section{Use of GPL-compatible licenses increases external contributions to code development while the use of GPL-incompatible licenses decreases these contributions}

While the company-specific licensing models are designed to protect the companies' right on the code and encourage contribution from individual and commercial developers, they also present a challenge to developers - the codebase must not be "contaminated" by contributions with incompatible licensing constraints. In fact, committers submitting code contributions must go over a pre-defined checklist that ensures that the contributed code is compatible with the company-specific license. The problem arises when a project wants to re-use existing work released under an incompatible license. After all, nobody in the community wants to waste their valuable time and resources recreating the wheel. Since GPL is the most popular license used by open source projects, the GPL-incompatibility may hinder the development of the project. For example, Sun is using the CDDL license for OpenSolaris which will not result in any "cross pollination" of Solaris and the Linux distributions. To drive more efficiency and cooperation between Linux and OpenSolaris, Sun is considering a dual-licensing move, Mozilla has switched to a triple license scheme to being compatible with GPL, and Eclipse Foundation is also 
working intensively on the possibility of switching to a multi-license scheme to solve the incompatibility problem.

\subsection{Recommendations to top management teams of large companies considering releasing proprietary code to an open source project}

Based on the insights generated, the following four recommendations are made to top management teams of large companies:

1. Release code as open source when the following conditions are present:

- The code does not provide the company with a strong competitive advantage or is a source of profits

- The competitive advantage or the profits the code provides are threatened by much stronger competitors

2. To profit from the release of code as open source, the company needs to:

- Make the code more attractive by increasing the value it offers potential customers, project contributors, and complementors as well as reduce its costs of developing the code

- Increase the exchange value of the commercial offerings linked to the open source software

3. To appropriate a greater portion of the value created by releasing the code as open source, the company must contribute more than others to the open source project, and exert subtle control over the project 
4. To increase the likelihood of success, large companies should release code for tools as open source instead of code for applications and operating systems

\section{Conditions conducive to a large company releasing code as open source}

A company may face one of the three situations when releasing the code as open source: (i) the software is new to the company and the market is dominated by single vendor; (ii) the software is losing market share to strong competitors; and (iii) the software needs more features and larger user-base. In all situations, the code does not provide the company with a strong competitive advantage or a source of profits, or the competitive advantage or the profits the code provides are threatened by much stronger competitors. But it does not mean the code is not strategically important to the company, the company expect releasing the code as open source to create new use value for the code and trigger the demands for their commercial offerings.

\section{What to do to profit from releasing code as open source}

The perceptions of other players on the code determine how much new use value the company can create for the released code with the help of external resources. In order to attract more customers, contributors to the open source project and complementors to join the company's value net, the company needs to provide perceived value for these players and clear the obstacles the potential customers, contributors to the open source project and complementors may encounter when getting involved in the open source projects.

Although use value can be increased by the efforts of open source communities, companies can only profit from the released code through their business models when 
realizing exchange value from the commercial offerings. Code release move may force the company to give up profiting from direct selling and resort to other revenue sources, or provide opportunities for the company to enhance or extend original revenue models. Companies have to be able to adjust their business models to increase the exchange value of the commercial offerings related to the open source software.

\section{How to appropriate more value}

As the donator of the code and originator of the open source project, the company that releases code has more incentives and advantages than others to appropriate value from the released code. The company may use the following means to ensure more contributions than others and maintain the leadership in an open source project: (i) remains the largest code and financial contributor; (ii) sends employees to open source community to influence the development; (iii) uses open source license to grant itself more power over others; (iv) only releases part of the code; (v) the code released is specific for the focal company's hardware. At the same time, the power of company over code evolution affects perceptions of external developers and third parties on the code. Companies have to balance the degree of contribution or leadership in an open source project with the control over the development process to attract more contributions. By contributing more, companies may influence the direction of the open source projects, absorb the new use value created by open source community and tailor it for their commercial offerings.

\section{What code to release}

In this research, development tools released by large companies attracted more third parties than applications and operating systems. Third-party companies have more 
space to develop value-added commercial offerings based on a common development tool than on applications such as a browser. Companies should release the code that has potential expansibility for other individuals, firms, and the company itself to build added value commercial offerings on. 


\section{CONCLUSIONS, LIMITATIONS, AND FUTURE RESEARCH}

This chapter is organized into three sections. Section 6.1 provides the main conclusions of this research. Section 6.2 describes the limitations of this research. Finally section 6.3 provides suggestions for future research.

\subsection{Conclusions}

This research uses the PARTS framework to examine six instances of Fortune 500 companies releasing their code to open source communities.

The first conclusion is that the large companies face difficult market situations at the time that they release their code as open source. The intent is to change the game to favor the company releasing the code. The "difficult situation" faced by the company in this research does not imply that the company is in trouble as a whole. What is meant is that the company has difficulties when creating value for the code on its own. The release of the code enables the large company to garner external resources to increase the customer value of the code and decrease the cost of developing and maintaining the code. The expected return from releasing the company's code as open source must be greater than the expected return of keeping the code closed. When the company releases code as open source it foregoes the opportunity to license the software for a fee and may provide competitors a competitive advantage (Henkel, 2003).

The second conclusion is that to increase profits, the large company must create use value and realize exchange value. Figure 7 suggests a model for the process of value creation and appropriation for code release. 
Figure 7: Value creation and value capture process for code release

\begin{tabular}{|c|c|c|c|}
\hline $\begin{array}{l}\text { Company A: releases } \\
\text { code as open source }\end{array}$ & $\begin{array}{l}\text { Open source } \\
\text { community: creates } \\
\text { new use value for the } \\
\text { code }\end{array}$ & $\begin{array}{l}\text { Company A: captures } \\
\text { new use value created } \\
\text { by open source } \\
\text { community and adds } \\
\text { new use value }\end{array}$ & $\begin{array}{l}\text { Company A: realizes } \\
\text { exchange value from } \\
\text { the commercial } \\
\text { offerings }\end{array}$ \\
\hline
\end{tabular}

Based on Bowman and Ambrosine (2000), it is argued with the model shown as Figure 7 that a large company must first create value working with the external resources that contribute to the open source project and then must realize exchange value through proprietary market offers.

The third conclusion is that operationalizing formal game theory (MacDonald \& Ryall, 2004) to examine instance of code release is not practical. To operationalize formal game theory, abundant data is required. Most of this data is not available. While the PARTS framework lacks the formality of other cooperative game methods, it was found to be useful for this research. 
The fourth conclusion is that the company that releases code has a better chance than other players to capture the use value from the open source project and tailor it for its commercial offerings.

The fifth conclusion is that a company can use five methods to limit the value others create thus increasing the value that it appropriates. The company can (i) become the main code and financial contributor; (ii) influence the development of the open source project; (iii) use the open source license to grant itself more power than others; (iv) release only part of the code; and (v) release code that is specific to the company's hardware.

The sixth conclusion is that the characteristics and type of code matter when companies pursue a strategy that entails the release of code as open source. The code chosen by companies to release is strategically important to the company but cannot be core to the company's profit generation ability.

The seventh conclusion is that the insights generated by using the PARTS framework will be different from using the value network (Christensen \& Rosenbloom, 1995) and the ecosystem perspective (Iansiti \& Levien, 2004). All of the three frameworks emphasize the relationship between the focal company and other companies around its business, while for this research topic, using the PARTS framework can assess how companies change the business game to favor themselves in the marketplace when releasing code as open source by examining five relevant aspects: players, added value, rules, tactics and scope. Using the value network perspective can assess if the company can create a value network with participants such as suppliers and 
channel partners by releasing code as open source and improve the products created by the value network, attract more customers, and take over the leadership position in the marketplace. Using the ecosystem perspective can assess the health of the ecosystem anchored the open source projects by examining the ecosystem's productivity, robustness, and the capacity to increase meaningful diversity through the creation of valuable new functions (Iansiti \& Levien, 2004).

\subsection{Limitations}

The research has at least four limitations.

First, the PARTS framework provided a lens to generate comprehensive insights, but it lacks the formality of methods such as the value appropriation framework provided by MacDonald and Ryall (2004).

Second, the research uses secondary data. Companies and open source projects were not contacted.

Third, only six instances are included in the sample of this research.

Fourth, the research method does not allow us to answer questions that require knowledge of executives' motivations not stated in press releases. Examples of these questions include: was the code released to distract competitors? reduce number of employees? 


\subsection{Future research}

The following suggestions are made for future research:

First, examine the shift of value chain when large companies release code as open source.

Second, compare the different situations or troubles faced by large companies and open source start-ups that encourage the companies to release code as open source.

Third, future research needs to differentiate between customers who pay for the code and users who do not. 


\section{REFERENCES}

Barney, J. B. 1991. Firm resources and sustained competitive advantage. Journal of Management, 17(1): 99-120.

Behlendorf, B. 1999. Open Source as a business strategy. In: DiBona, C., Ockman, S. and Stone, M. Open Sources - Voices from the Open Source Revolution. Cambridge MA et al.: O'Reilly.

Bogner, W. C., Thomas, H. \& McGee, J. 1999. Core competence and competitive advantage: Towards a dynamic model. British Journal of Management, 10: 275290.

Bonaccorsi, A. \& Rossi, C. 2004. Comparing motivations of individual programmers and firms to take part in the open source movement. From community to business. http://opensource.mit.edu/papers/bnaccorsirossimotivationlong.pdf.

Bonaccorsi, A. \& Rossi, C. 2005. Licensing schemes in the production and distribution of open source software. An empirical investigation. http://opensource.mit.edu/papers/bnaccorsirossilicense.pdf.

Bowman, C. \& Ambrosini, V. 2000. Value creation versus value capture: Towards a coherent definition of value in strategy. British Journal of Management, 11: 115.

Brandenburger, A. M. \& Nalebuff, B. J. 1996. Coopetition. Bantam Doubleday Dell Publishing Group, Inc.

Brandenburger, A. M. \& Stuart, H. W. 1996. Value-based strategy. Journal of Economics \& Management Strategy, 5:5-24. 
Chesbrough, H. \& Rosenbloom, R. S. 2002. The role of the business model in capturing value from innovation: evidence from Xerox Corporation's technology spin-off companies. Industry and Corporate Change, 11(3): 529-555.

Christensen, C. M. \& Rosenbloom, R. S. 1995. Explaining the Attacker's Advantage: Technological Paradigms, Organizational Dynamics, and the Value Network. Research Policy, 24(2): 233-257.

Cover, R. 2005. Sun releases Solaris operating system and 1600 patents under CDDL open source license. http://xml.coverpages.org/ni2005-01-27-a.html.

Fink, M. 2003. The business and economics of Linux and open source. Prentience Hall, Upper Saddle River, NJ.

Galli, P. 2005. IBM gives 500 patents to open-source developers. http://www.eweek.com/article2/0,1895,1750358,00.asp.

Gans, J. 2005. Core economics for managers. University of Melbourne.

Gabriel, R. P. \& Goldman, R. 2005. Innovation happens elsewhere. Morgan Kaufmann Publishers.

Gabriel R. P. \& Goldman R. 2002. Open source: beyond the fairytales. http://opensource.mit.edu/papers/gabrielgoldman.pdf. 
Godfrey, M. W. \& Tu, Q. 2000. Evolution in open source software: A case study. Proceedings 2000 International Conference. Software Maintenance (ICSM-00), San Jose, California.

Hars, A. \& Ou, S. 2002. Working for Free? Motivations for Participating in OpenSource Projects. International Journal of Electronic Commerce, 6(3): 25-39.

Hawkins, R.E. 2004. The economics of open source software for a competitive firm: why give it free? Netnomics, 6: 103-117.

Hecker, F. 1999. Setting up shop: The business of open-source software. IEEE Software, 16(1): 45-51.

Henkel, J. 2003. Open source software from commercial firms - Tools, complements, and collective invention. http://www.inno-tec.bwl.unimuenchen.de/forschung/henkel/OSS JHenkel 2003-05.pdf.

Henkel, J. 2004. Patterns of free revealing - balancing code sharing and protection in commercial open source development. http://opensource.mit.edu/papers/henkel2.pdf

Hertel, G., Niedner, S. \& Herrmann, S. 2003. Motivation of software developers in open source projects: An Internet-based survey of contributors to the Linux kernel. Research Policy, 32: 1159-1177.

Hope, J. 2003. Open source as a business approach. Research School of Social Sciences, Australian National University, Canberra, ACT 0200. http://rsss.anu.edu.au/ janeth/OSBusMod.html\#d8. 
Iansiti, M. \& Levien, R. 2004. Strategy as ecology. Harvard Business Review, 82(3): 68-79.

Kasper, E. 2001. Epistemic communities, situated learning and open source software development. http://opensource.mit.edu/papers/kasperedwards-ec.pdf.

Koenig, J. 2004. Seven open source business strategies for competitive advantage. IT Manager's Journal, May 14.

Lakhani, K. R., Wolf, B. \& Bates, J. 2002. The Boston Consulting Group Hacker Survey. Boston Consulting Group, Boston. http://www.ostg.com/bcg/BCGHACKERSURVEY.pdf.

Lakhani, K. \& von Hippel, E. 2003. How Open Source software works: "free" userto-user assistance. Research Policy, 32(6): 923-943.

Lerner, J. \& Tirole, J. 2002a. Some simple economics of open source. The Journal of Industrial Economics, 50: 197-234.

Lecocq, X. \& Demil, B. 2002. Open Standard: Role of externalities and impact on the industry structure. http://opensource.mit.edu/papers/lecocqdemil.pdf.

Lerner, J. \& Tirole, J. 2002b. The Scope of Open Source Licensing. http://www.people.hbs.edu/jlerner/OSLicense.pdf.

Lerner, J. \& Tirole, J. 2004. The economics of technology sharing: open source and beyond. http://www.nber.org/papers/W10956. 
MacDonald, G. \& Ryall, M.D. 2004. How do value creation and competitive determine whether a firm appropriates value? Management Science, 50: 13191333.

Moczar, L. 2005. The economics of commercial open source. Galatea Information Strategies. http://www.galatea.com/economics.html.

Morris, M., Schindehutte, M. \& Allen, J. 2005. The entrepreneur's business model: toward a unified perspective. Journal of Business Research, 58: 726-735.

Niccolai, J. 2005. Mozilla creates commercial subsidiary. http://www.computerworld.com/developmenttopics/development/webdev/story/0, $10801,103640,00 . \mathrm{html}$.

Nilendu, P. \& Madanmohan, T. R. 2002. Competing on open source: strategies and practice. http://opensource.mit.edu/papers/madanmohan.pdf.

Nissila, J. 2004. Towards a Better Understanding of Open Source Business Models. http://w3.msi.vxu.se/users/per/IRIS27/iris27-1202.pdf.

Open Source Initiative, 2005, http://www.opensource.org.

Peteraf, M. \& Shanley, M. 1997. Getting to know you: A theory of strategic group identity. Strategic Management Journal, 18 (Special Issue): 165-186.

Raymond, E. S. 1999. The Cathedral and the bazaar: Musings on Linux and open source by an accidental revolutionary. Sebastopol: O'Reilly. 
Rota, S., von Wartburg, M., \& Osterloh, M. 2002. Trust and commerce in Open Source - a contradiction? MIT Working Paper. http://www.wiwiss.fuberlin.de/w3/w3sydow/EURAM/pdf_2002/EURAM\%20Paper\%20Rota\%20et\%2 0al.pdf

Schadler, T., Rutstein, C., Lambert, N., Tseng, A., \& Whiteley, R. 2003. Your open source strategy. The TechStrategy Report, Forrest Research Inc.

Shapiro, C. \& Varian, H. R. 1999. The art of standards wars. California Management Review, 41(2): 8-32.

Spiller, D. \& Wichmann, T. 2002. Basics of open source software markets and business models. Free/Libre Open Source Software: Survey and Study. Berlin, Berlecon Research GmbH.

Stallman, R. M. 1996. GNU Emacs Manual, version 19.33. Free Software Foundation, Boston, MA.

Timmers, P. 1998. Business Models for Electronic Markets. EMInternational Journal of Electronic Markets, 8(2): 3-8.

Valimaki, M. \& Oksanen, V. 2002. Evaluation of open source licensing models for a company developing mass market software. The Proceedings of International Conference on Law and Technology, Cambridge, MA.

von Hippel, E. 2002. Open source projects as horizontal innovation networks - by and for users. SSRN Working paper. http://papers.ssrn.com/sol3/delivery.cfm/SSRN_ID328900_code020906590.pdf?a bstractid $=328900$. 
von Hippel, E. \& von Krogh, G. 2003. Open source software and the "privatecollective" innovation model: Issues for organization science. Organization Science, 14(2): 209-223.

von Krogh, G., Spaeth, S., \& Lakhani, K. 2003. Community, joining, and specialization in Open Source software innovation: a case study. Research Policy, 32(7): 1217-1241.

West, J. 2003. How open is open enough? Melding proprietary and open source platform strategies. Research Policy, (32): 1259-1285.

Wichmann, T. 2002. Firms' Open Source activities: motivations and policy implications. Free/Libre and Open Source Software: Survey and Study, FLOSS Final Report, International Institute of Infonomics, Berlecom Research GmbH. http://www.berlecon.de/studien/downloads/200207FLOSS_Activities.pdf.

Working group on Libre Software (Daffara, C. et al.). 2000. Free software / open source: Information society opportunities for Europe? Working paper. http://eu.conecta.it/paper.pdf.

Yang, J. 2005. Sales generated using open source software projects. Carleton University thesis, Ottawa, Canada. 


\section{LIST OF APPENDICES}

Appendix A: List of instances of a company releasing code to an open source project identified using online searches

\begin{tabular}{|c|c|c|c|c|c|}
\hline \multirow[t]{2}{*}{ Company } & \multirow[t]{2}{*}{ OSS project } & \multicolumn{3}{|c|}{ Meet sample selection criteria? } & \multirow{2}{*}{$\begin{array}{l}\text { Include in the } \\
\text { sample? }\end{array}$} \\
\hline & & $\begin{array}{l}\text { a. Released } \\
\text { between } 1998 \text { and } \\
2005 ?\end{array}$ & $\begin{array}{l}\text { b. Fortune } 500 \\
\text { company in } 2005 ?\end{array}$ & $\begin{array}{l}\text { c. Data is } \\
\text { available on the } \\
\text { Web? }\end{array}$ & \\
\hline $\begin{array}{l}\text { Apple } \\
\text { (www.apple.com) }\end{array}$ & Darwin & YES (1999) & YES & YES & YES \\
\hline $\begin{array}{l}\text { Apple } \\
\text { (www.apple.com) }\end{array}$ & Rendezvous & YES (2002) & YES & NO & NO \\
\hline $\begin{array}{l}\text { AOL } \\
\text { (www.aol.com) }\end{array}$ & AOLserver & YES (1999) & YES & NO & NO \\
\hline $\begin{array}{l}\text { BEA } \\
\text { (www.bea.com) }\end{array}$ & Beehive & YES (2004) & NO & NO & $\mathrm{NO}$ \\
\hline $\begin{array}{l}\text { Cisco } \\
\text { (www.cisco.com) }\end{array}$ & 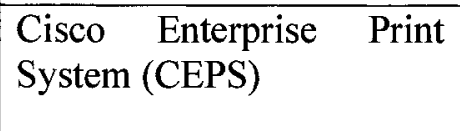 & YES (2000) & YES & NO & NO \\
\hline $\begin{array}{l}\text { db4objects } \\
\text { (www.db4o.com) }\end{array}$ & $\mathrm{db} 4 \mathrm{o}$ & YES (2004) & $\mathrm{NO}$ & YES & NO \\
\hline $\begin{array}{l}\text { Duke Power } \\
\text { (www.dukepower.com) }\end{array}$ & $\begin{array}{l}\text { Duke Open Source } \\
\text { Framework }\end{array}$ & YES (2004) & YES & NO & NO \\
\hline
\end{tabular}




\begin{tabular}{|c|c|c|c|c|c|}
\hline $\begin{array}{l}\text { Gluecode Software } \\
\text { (acquired by IBM in 2005) }\end{array}$ & Gluecode JOE & YES (2004) & YES & NO & $\mathrm{NO}$ \\
\hline $\begin{array}{l}\text { IBM } \\
\text { (www.ibm.com) }\end{array}$ & Cloudscape database & YES (2004) & YES & $\mathrm{NO}$ & $\mathrm{NO}$ \\
\hline $\begin{array}{l}\text { IBM } \\
\text { (www.ibm.com) }\end{array}$ & Eclipse & YES (2001) & YES & YES & YES \\
\hline $\begin{array}{l}\text { IBM } \\
\text { (www.ibm.com) }\end{array}$ & $\begin{array}{l}\text { Reusable Dialog } \\
\text { Components (RDC) }\end{array}$ & YES (2004) & YES & NO & NO \\
\hline $\begin{array}{l}\text { Microsoft } \\
\text { (www.microsoft.com) }\end{array}$ & FlexWiki & YES (2004) & YES & $\mathrm{NO}$ & NO \\
\hline $\begin{array}{l}\text { Microsoft } \\
\text { (www.microsoft.com) }\end{array}$ & $\begin{array}{l}\text { Windows Template } \\
\text { Library (WTL) }\end{array}$ & YES (2004) & YES & NO & $\mathrm{NO}$ \\
\hline $\begin{array}{l}\text { Microsoft } \\
\text { (www.microsoft.com) }\end{array}$ & $\mathrm{WiX}$ & YES (2004) & YES & NO & $\mathrm{NO}$ \\
\hline $\begin{array}{l}\text { Netscape (acquired by } \\
\text { AOL in 1998) } \\
\text { (www.netscape.com) }\end{array}$ & Mozilla & YES (1998) & YES & YES & YES \\
\hline $\begin{array}{l}\text { SGI } \\
\text { (www.sgi.com) }\end{array}$ & XFS & YES (1999) & $\mathrm{NO}$ & $\mathrm{NO}$ & NO \\
\hline $\begin{array}{l}\text { Sun } \\
\text { (www.sun.com) }\end{array}$ & DRM & YES (2005) & YES & NO & NO \\
\hline
\end{tabular}




\begin{tabular}{|c|c|c|c|c|c|}
\hline $\begin{array}{l}\text { Sun } \\
\text { (www.sun.com) }\end{array}$ & $\begin{array}{l}\text { Identify Management } \\
\text { Apps }\end{array}$ & YES (2005) & YES & $\mathrm{NO}$ & $\mathrm{NO}$ \\
\hline $\begin{array}{l}\text { Sun } \\
\text { (www.sun.com) }\end{array}$ & JSR 134 & YES (2003) & YES & $\mathrm{NO}$ & $\mathrm{NO}$ \\
\hline $\begin{array}{l}\text { Sun } \\
\text { (www.sun.com) }\end{array}$ & Netbeans & YES (2000) & YES & YES & YES \\
\hline $\begin{array}{l}\text { Sun } \\
\text { (www.sun.com) }\end{array}$ & OpenOffice.org & YES (2000) & YES & YES & YES \\
\hline $\begin{array}{l}\text { Sun } \\
\text { (www.sun.com) }\end{array}$ & $\begin{array}{l}\text { Open Source Web Single } \\
\text { Sign-On (OpenSSO) }\end{array}$ & YES (2005) & YES & $\mathrm{NO}$ & $\mathrm{NO}$ \\
\hline $\begin{array}{l}\text { Sun } \\
\text { (www.sun.com) }\end{array}$ & OpenSolaris & YES (2005) & YES & YES & YES \\
\hline
\end{tabular}


Appendix B: Information on the research sample

\begin{tabular}{|c|c|c|c|c|c|c|c|c|c|}
\hline No. & $\begin{array}{l}\text { Open source } \\
\text { project }\end{array}$ & Company & $\begin{array}{l}\text { Year of } \\
\text { release }\end{array}$ & Type of code & $\begin{array}{l}\text { Intended users } \\
\text { of code }\end{array}$ & Main motives of release & $\begin{array}{l}\text { Situations faced } \\
\text { before code } \\
\text { release }\end{array}$ & $\begin{array}{l}\text { Open source } \\
\text { license used }\end{array}$ & $\begin{array}{l}\text { Commercial } \\
\text { offering(s) }\end{array}$ \\
\hline 1 & Mozilla & $\begin{array}{l}\text { Netscape/ } \\
\text { AOL }\end{array}$ & 1998 & $\begin{array}{l}\text { Networking/Int } \\
\text { ernet } \\
\text { application }\end{array}$ & End-user & $\begin{array}{l}\text { - Drive a turnaround of } \\
\text { the business } \\
\text { - Corner Microsoft }\end{array}$ & $\begin{array}{l}\text { - Losing market } \\
\text { to IE }\end{array}$ & $\begin{array}{l}\text { NPL (retired) } \\
\text { MPL/GPL/L } \\
\text { GPL }\end{array}$ & $\begin{array}{l}\text { Netscape } \\
\text { browser }\end{array}$ \\
\hline 2 & Darwin & Apple & 1999 & $\begin{array}{l}\text { Operating } \\
\text { system } \\
\text { (partly } \\
\text { released) }\end{array}$ & End-user & $\begin{array}{l}\text { - Provide better codebase } \\
\text { for Mac OS X }\end{array}$ & $\begin{array}{l}\text { - Mac OS X } \\
\text { needed more } \\
\text { users and } \\
\text { advanced } \\
\text { features } \\
\end{array}$ & APSL & Mac OS X \\
\hline 3 & Netbeans & Sun & 2000 & $\begin{array}{l}\text { Development } \\
\text { tool }\end{array}$ & Developer & $\begin{array}{l}\text { - Expand developer and } \\
\text { ISV community around } \\
\text { Java technology }\end{array}$ & $\begin{array}{l}\text { - The product } \\
\text { needed more } \\
\text { users and } \\
\text { features }\end{array}$ & SPL & $\begin{array}{l}\text { Sun Java } \\
\text { studio tools }\end{array}$ \\
\hline 4 & OpenOffice.org & Sun & 2000 & $\begin{array}{l}\text { Productivity } \\
\text { application }\end{array}$ & End-user & $\begin{array}{l}\text { - Corner Microsoft } \\
\text { - Make hardware more } \\
\text { appealing }\end{array}$ & $\begin{array}{l}\text { The product } \\
\text { was new to the } \\
\text { company } \\
\text { - Monopolized } \\
\text { market }\end{array}$ & $\begin{array}{l}\text { SISSL } \\
\text { (retired) } \\
\text { LGPL }\end{array}$ & StarOffice \\
\hline 5 & Eclipse & IBM & 2001 & $\begin{array}{l}\text { Development } \\
\text { tool }\end{array}$ & Developer & $\begin{array}{l}\text { - Set standard } \\
\text { - Corner Microsoft }\end{array}$ & $\begin{array}{l}\text { - The product } \\
\text { needed more } \\
\text { user and features }\end{array}$ & $\begin{array}{l}\text { CPL (retired) } \\
\text { EPL }\end{array}$ & $\begin{array}{l}\text { WebSphere } \\
\text { studio tools }\end{array}$ \\
\hline 6 & OpenSolaris & Sun & 2005 & $\begin{array}{l}\text { Operating } \\
\text { system } \\
\text { (partly } \\
\text { released) }\end{array}$ & $\begin{array}{l}\text { System } \\
\text { administrator }\end{array}$ & $\begin{array}{l}\text { - Corner Linux and } \\
\text { Windows }\end{array}$ & $\begin{array}{l}\text { - Losing market } \\
\text { to Linux }\end{array}$ & CDDL & Solaris \\
\hline
\end{tabular}


Appendix C: Changes in players in the company's value net

\begin{tabular}{|c|c|c|c|c|c|c|c|c|}
\hline \multirow[b]{2}{*}{ Instance } & \multicolumn{3}{|c|}{ Added players } & \multicolumn{4}{|c|}{ Changed players' roles } & \multirow{2}{*}{\begin{tabular}{|l|}
$\begin{array}{l}\text { Became a } \\
\text { player }\end{array}$ \\
Company that \\
released code \\
became a \\
player in a \\
monopoly like \\
market
\end{tabular}} \\
\hline & $\begin{array}{l}\text { Added } \\
\text { customers }\end{array}$ & $\begin{array}{l}\text { Added } \\
\text { suppliers }\end{array}$ & $\begin{array}{l}\text { Added } \\
\text { complementors }\end{array}$ & $\begin{array}{l}\text { Changed } \\
\text { customers into } \\
\text { suppliers }\end{array}$ & $\begin{array}{l}\text { Changed } \\
\text { complementors } \\
\text { into suppliers }\end{array}$ & $\begin{array}{l}\text { Changed } \\
\text { competitors } \\
\text { into suppliers }\end{array}$ & $\begin{array}{l}\text { Changed } \\
\text { competitors } \\
\text { into } \\
\text { complementors }\end{array}$ & \\
\hline $\begin{array}{l}\text { Mozilla/Netscape/ } \\
\text { AOL }\end{array}$ & $\begin{array}{l}\text { - Individual } \\
\text { users }\end{array}$ & $\begin{array}{l}\text { - External } \\
\text { developers } \\
\text { - Third parties }\end{array}$ & $\begin{array}{l}\text { - Hardware and } \\
\text { software vendors } \\
\text { - Distributors }\end{array}$ & $\begin{array}{l}\text { - Users become } \\
\text { contributors } \\
\text { - Third parties } \\
\text { become } \\
\text { contributors }\end{array}$ & $\begin{array}{l}\text { Vendors invest } \\
\text { developers and } \\
\text { other resources } \\
\text { to the project }\end{array}$ & & & \\
\hline Darwin/Apple & \begin{tabular}{|l} 
- Individual \\
users \\
- University \\
users \\
\end{tabular} & $\begin{array}{l}\text { - External } \\
\text { developers }\end{array}$ & & $\begin{array}{l}\text { - Users become } \\
\text { contributors }\end{array}$ & & & & \\
\hline Netbeans/Sun & $\begin{array}{l}\text { - Individual } \\
\text { users } \\
\text { - Corporate } \\
\text { users }\end{array}$ & \begin{tabular}{|l} 
- External \\
developers \\
- Third parties
\end{tabular} & $\begin{array}{l}\text { - Hardware and } \\
\text { software vendors } \\
\text { - Plug-in } \\
\text { providers } \\
\text { - Distributors }\end{array}$ & $\begin{array}{l}\text { - Users become } \\
\text { contributors } \\
\text { - Third parties } \\
\text { become } \\
\text { contributors }\end{array}$ & $\begin{array}{l}\text { Vendors invest } \\
\text { developers and } \\
\text { other resources } \\
\text { to the project }\end{array}$ & $\begin{array}{l}\text { Other IDE } \\
\text { vendors join to } \\
\text { contribute }\end{array}$ & $\begin{array}{l}\text { Other IDE } \\
\text { vendors use the } \\
\text { same codebase } \\
\text { and add features } \\
\text { for the code }\end{array}$ & \\
\hline OpenOffice.org/Sun & $\begin{array}{l}\cdot \text { Individual } \\
\text { users } \\
\text { - Corporate } \\
\text { users } \\
\text { - University } \\
\text { users } \\
\text { - Government } \\
\text { users } \\
\end{array}$ & $\begin{array}{l}\text { - External } \\
\text { - Third parties }\end{array}$ & $\begin{array}{l}\text { - Hardware and } \\
\text { software vendors } \\
\text { - Distributors }\end{array}$ & $\begin{array}{l}\text { Users become } \\
\text { contributors }\end{array}$ & $\begin{array}{l}\text { Vendors invest } \\
\text { developers and } \\
\text { other resources } \\
\text { to the project }\end{array}$ & & & $\begin{array}{l}\text { - Enter the } \\
\text { market } \\
\text { dominated by } \\
\text { Microsoft's } \\
\text { Office and gain } \\
\text { market share }\end{array}$ \\
\hline
\end{tabular}




\begin{tabular}{|c|c|c|c|c|c|c|c|c|}
\hline Eclipse/IBM & $\begin{array}{l}\text { - Individual } \\
\text { users } \\
\text { - Corporate } \\
\text { users }\end{array}$ & $\begin{array}{l}\text { - External } \\
\text { developers } \\
\text { - Third parties }\end{array}$ & $\begin{array}{l}\text { - Hardware and } \\
\text { software vendors } \\
\text { - Plug-in } \\
\text { providers } \\
\text { - Other } \\
\text { organizations } \\
\text { (i.e. non-profits, } \\
\text { universities, } \\
\text { publishers) }\end{array}$ & $\begin{array}{l}\text { Users become } \\
\text { contributors } \\
\text { - Third parties } \\
\text { become } \\
\text { contributors }\end{array}$ & $\begin{array}{l}\text { Vendors invest } \\
\text { developers and } \\
\text { other resources } \\
\text { to the project }\end{array}$ & $\begin{array}{l}\text { Other IDE } \\
\text { vendors join to } \\
\text { contribute }\end{array}$ & $\begin{array}{l}\text { Other IDE } \\
\text { vendors use the } \\
\text { same codebase } \\
\text { and add features } \\
\text { for the code }\end{array}$ & \\
\hline OpenSolaris/Sun & $\begin{array}{l}\text { - Individual } \\
\text { users } \\
\text { - Corporate } \\
\text { users } \\
\text { - University } \\
\text { users }\end{array}$ & $\begin{array}{l}\text { External } \\
\text { developers }\end{array}$ & & $\begin{array}{l}\text { - Users become } \\
\text { contributors }\end{array}$ & & & & \\
\hline Count & 6 & 6 & 4 & 6 & 4 & 2 & 2 & 1 \\
\hline
\end{tabular}




\section{Appendix D: How releasing code to an open source project increases a large company's added value}

\begin{tabular}{|c|c|c|}
\hline Instance & Increase $\mathrm{V}$ & Decrease $V_{-i}$ \\
\hline Mozilla/Netscape/AOL & $\begin{array}{l}\text { Increased value of code } \\
\text { - Increased user base } \\
\text { - Improved quality } \\
\text { - Improved functionality } \\
\text { - More applications built on the code (over } 145 \text { extensions) } \\
\text { - Support more than } 12 \text { operating system/hardware platforms } \\
\text { - Support more than } 100 \text { languages } \\
\text { Reduced costs } \\
\text { - Cost is lowered by getting volunteer developers } \\
\text { - Cost is lowered by getting third parties' contributions }\end{array}$ & $\begin{array}{l}\text { Reduced or constrained the added value of other players } \\
\text { Netscape/AOL remains the largest code and financial contributor } \\
\text { NPL (Mozilla's first license) granted Netscape additional rights over the } \\
\text { code } \\
\text { - Most module owners are Netscape employees } \\
\text { Decrease } V_{-i} \text { by decreasing the added value of competitors } \\
\text { - Gaining market share from Microsoft's IE }\end{array}$ \\
\hline Darwin/Apple & $\begin{array}{l}\text { Increased value of code } \\
\text { - Increased user base } \\
\text { - Support PowerPC and Intel }\end{array}$ & $\begin{array}{l}\text { Reduced or constrained the added value of other players } \\
\text { - Apple remains the largest code and financial contributor } \\
\text { - One of the three members of the core team is an Apple employee }\end{array}$ \\
\hline
\end{tabular}




\begin{tabular}{|c|c|c|}
\hline & $\begin{array}{l}\text { More applications built on the code } \\
\text { Reduced costs } \\
\text { - Cost is lowered by getting volunteer developers }\end{array}$ & $\begin{array}{l}\text { The code is partly released } \\
\text { - Darwin is specific to Apple's hardware }\end{array}$ \\
\hline Netbeans/Sun & $\begin{array}{l}\text { Increased value of code } \\
\text { - Increased user base } \\
\text { - Improved quality } \\
\text { - Improved functionality } \\
\text { - More applications built on the code } \\
\text { Reduced costs } \\
\text { - Cost is lowered by getting volunteer developers } \\
\cdot \text { Cost is lowered by getting third parties' contributions }\end{array}$ & $\begin{array}{l}\text { Reduced or constrained the added value of other players } \\
\text { - Sun remains the largest code and financial contributor } \\
\text { - One of the board members is always appointed by Sun }\end{array}$ \\
\hline OpenOffice.org/Sun & $\begin{array}{l}\text { Increased value of code } \\
\text { - Improved quality } \\
\text { - Improved functionality } \\
\text { - Support multiple platforms and languages }\end{array}$ & $\begin{array}{l}\text { Reduced or constrained the added value of other players } \\
\text { - Sun remains the largest code and financial contributor } \\
\text { - Two of the nine council members are always Sun employees }\end{array}$ \\
\hline
\end{tabular}




\begin{tabular}{|c|c|c|}
\hline & $\begin{array}{l}\text { Support Open Document Format } \\
\text { Reduced costs } \\
\text { - Cost is lowered by getting volunteer developers } \\
\text { - Cost is lowered by getting third parties' contributions }\end{array}$ & $\begin{array}{l}\text { Decrease } V_{-i} \text { by decreasing the added value of competitors } \\
\text { - Gaining market share from Microsoft's Office } \\
\text { - Microsoft reacted by reducing price }\end{array}$ \\
\hline Eclipse/IBM & $\begin{array}{l}\text { Increased value of code } \\
\text { - Increased user base } \\
\text { - Improved quality } \\
\text { - Improved functionality } \\
\text { - More applications built on the code } \\
\text { - Set a standard } \\
\text { Reduced costs } \\
\text { - Cost is lowered by getting volunteer developers } \\
\text { - Cost is lowered by getting third parties' contributions }\end{array}$ & $\begin{array}{l}\text { Reduced or constrained the added value of other players } \\
\text { IBM remains the largest code and financial contributor } \\
\text { IBM is a strategic member and hold a seat in the community board } \\
\text { Decrease } \mathrm{V}_{-\mathrm{i}} \text { by decreasing the added value of competitors } \\
\text { - Growing in market share } \\
\text { - Become the most popular Java IDE }\end{array}$ \\
\hline OpenSolaris/Sun & $\begin{array}{l}\text { Increased value of code } \\
\text { - Increased user base }\end{array}$ & $\begin{array}{l}\text { Reduced or constrained the added value of other players } \\
\text { - Sun remains the largest code and financial contributor }\end{array}$ \\
\hline
\end{tabular}




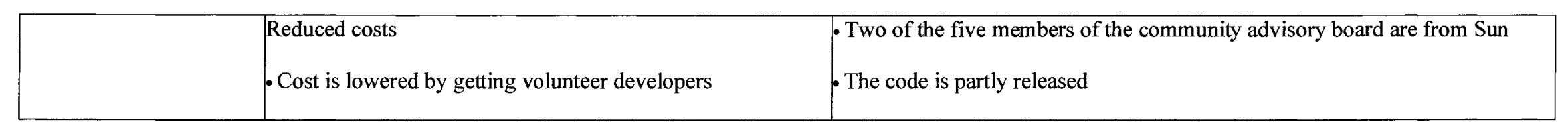


Appendix E: Factors that encourage or discourage developers and third parties to contribute to the open source project

\begin{tabular}{|l|l|l|}
\hline Instance & Perceptions of external developers & Perceptions of third parties \\
\hline Mozilla/Netscape/AOL & $\begin{array}{l}\text { The power of the company on the code } \\
\text { NPL aroused criticism in open source community because it granted }\end{array}$ & \\
& $\begin{array}{l}\text { Type and characteristics of the code } \\
\text { External developers found it difficult to understand the complex } \\
\text { Navigator codebase when it was released } \\
- \text { Mozilla was complained in its early days for the incomplete code } \\
\text { released by Netscape }\end{array}$ & \\
& $\begin{array}{l}\text { License } \\
\text { Mozilla switched to GPL-compatible triple license scheme to attract } \\
\text { more developers }\end{array}$ & \\
\hline Darwin/Apple & The power of the company on the code \\
Developers perceived the development process as not open and & \\
\hline
\end{tabular}




\begin{tabular}{|c|c|c|}
\hline & transparent & \\
\hline Netbeans/Sun & $\begin{array}{l}\text { The power of the company on the code } \\
\text { Sun was accused of dominating the development process to its } \\
\text { advantage }\end{array}$ & $\begin{array}{l}\text { The power of the company on the code } \\
\text {. Netbeans was perceived as being dominated by Sun } \\
\text { Type and characteristics of the code } \\
\text { Vendors consider Netbeans as a commoditized platform to add } \\
\text { value on ( } 66 \text { partners) }\end{array}$ \\
\hline OpenOffice.org/Sun & $\begin{array}{l}\text { The power of the company on the code } \\
\text { - Sun's support caused suspicion } \\
\text { Type and characteristics of the code } \\
\text { External developers found it difficult to understand the large codebase }\end{array}$ & \\
\hline Eclipse/IBM & $\begin{array}{l}\text { The power of the company on the code } \\
\text {-IBM's spinning out Eclipse Foundation made developers perceive } \\
\text { Eclipse as more independent }\end{array}$ & $\begin{array}{l}\text { The power of the company on the code } \\
\text { Eclipse encountered initial skepticism about its ability to get out } \\
\text { of the shadow of IBM } \\
\text { IBM's spinning out Eclipse Foundation boosted the growth of } \\
\text { company members }\end{array}$ \\
\hline
\end{tabular}




\begin{tabular}{|c|c|c|}
\hline & & $\begin{array}{l}\text { Type and characteristics of the code } \\
\text {-Vendors see Eclipse as a standardized platform to add value on } \\
\text { (114 partners) } \\
\text { License } \\
\text { Eclipse Foundation is working intensively to solve the GPL- } \\
\text { incompatibility problem }\end{array}$ \\
\hline OpenSolaris/Sun & $\begin{array}{l}\text { The power of the company on the code } \\
\text { Sun was criticized for trying to control the development process } \\
\text { License } \\
\text { CDDL inhibits programmers from intermingling the code with Linux. } \\
\text { Sun is considering a dual-licensing move to attract more developers }\end{array}$ & \\
\hline
\end{tabular}


Appendix F: Revenue models before and after the code was released

\begin{tabular}{|c|c|c|c|c|c|c|c|c|}
\hline \multirow[t]{2}{*}{ Instance } & \multicolumn{4}{|c|}{ Revenue models before code release } & \multicolumn{4}{|c|}{ Revenue models after code release } \\
\hline & $\begin{array}{l}\text { sales of } \\
\text { proprietary } \\
\text { software }\end{array}$ & $\begin{array}{l}\text { sales of } \\
\text { support } \\
\text { services }\end{array}$ & $\begin{array}{l}\text { increased } \\
\text { sales of } \\
\text { hardware } \\
\text { that includes } \\
\text { OSS }\end{array}$ & $\begin{array}{l}\text { other } \\
\text { indirect } \\
\text { benefits }\end{array}$ & $\begin{array}{l}\text { sales of } \\
\text { proprietary } \\
\text { software }\end{array}$ & $\begin{array}{l}\text { sales of } \\
\text { support } \\
\text { services }\end{array}$ & $\begin{array}{l}\text { increased } \\
\text { sales of } \\
\text { hardware } \\
\text { that includes } \\
\text { OSS }\end{array}$ & $\begin{array}{l}\text { other } \\
\text { indirect } \\
\text { benefits }\end{array}$ \\
\hline Mozilla/Netscape/AOL & $\begin{array}{l}\text { - Licensing fees } \\
\text { for Netscape } \\
\text { Navigator client } \\
\text { and enterprise } \\
\text { software }\end{array}$ & $\begin{array}{l}\text { - Support of } \\
\text { Netscape } \\
\text { Navigator client } \\
\text { and enterprise } \\
\text { software }\end{array}$ & & & & $\begin{array}{l}\text { - Support of } \\
\text { Netscape } \\
\text { browser }\end{array}$ & & $\begin{array}{l}\text { - Additional } \\
\text { profits from } \\
\text { portal sites }\end{array}$ \\
\hline Darwin/Apple & $\begin{array}{l}\text { - Licensing fees } \\
\text { for Mac OS X }\end{array}$ & $\begin{array}{l}\text { - Support of } \\
\text { Mac OS X }\end{array}$ & $\begin{array}{l}\text { - Sales of } \\
\text { Macintosh } \\
\text { computers }\end{array}$ & & $\begin{array}{l}\text { Licensing fees } \\
\text { for Mac OS X }\end{array}$ & $\begin{array}{l}\text { - Support of } \\
\text { Mac OS X }\end{array}$ & $\begin{array}{l}\text { - Sales of } \\
\text { Macintosh } \\
\text { computers }\end{array}$ & \\
\hline Netbeans/Sun & $\begin{array}{l}\text { - Licensing fees } \\
\text { for Sun Java } \\
\text { studio tools }\end{array}$ & $\begin{array}{l}\text { Support of } \\
\text { Sun Java studio } \\
\text { tools }\end{array}$ & $\begin{array}{l}\text { Sales of Sun } \\
\text { servers }\end{array}$ & & $\begin{array}{l}\text { - Licensing fees } \\
\text { for Sun Java } \\
\text { studio tools }\end{array}$ & $\begin{array}{l}\text { - Support of } \\
\text { Sun Java studio } \\
\text { tools }\end{array}$ & $\begin{array}{l}\text { - Sales of Sun } \\
\text { servers }\end{array}$ & \\
\hline OpenOffice.org/Sun & & & - Sales of Sun & & - Licensing fees & - Support of & - Sales of Sun & \\
\hline
\end{tabular}




\begin{tabular}{|c|c|c|c|c|c|c|}
\hline & & & servers & for StarOffice & StarOffice & servers \\
\hline Eclipse/IBM & $\begin{array}{l}\text { - Licensing fees } \\
\text { for WebShpere } \\
\text { studio tools }\end{array}$ & $\begin{array}{l}\text { - Support of } \\
\text { WebShpere } \\
\text { studio tools }\end{array}$ & $\begin{array}{l}\text { - Sales of IBM } \\
\text { servers }\end{array}$ & $\begin{array}{l}\text { Licensing fees } \\
\text { for WebShpere } \\
\text { studio tools }\end{array}$ & $\begin{array}{l}\text { - Support of } \\
\text { WebShpere } \\
\text { studio tools }\end{array}$ & $\begin{array}{l}\text { - Sales of IBM } \\
\text { servers }\end{array}$ \\
\hline OpenSolaris/Sun & $\begin{array}{l}\text { - Licensing fees } \\
\text { for Solaris } \\
\text { operating } \\
\text { system }\end{array}$ & $\begin{array}{l}\text { Support of } \\
\text { Solaris } \\
\text { operating } \\
\text { system }\end{array}$ & & & $\begin{array}{l}\text { Support of } \\
\text { Solaris } \\
\text { operating } \\
\text { system }\end{array}$ & $\begin{array}{l}\text { - Sales of Sun } \\
\text { servers }\end{array}$ \\
\hline
\end{tabular}


Appendix G: Company related benefits and risks of releasing code as open source:

\begin{tabular}{|c|c|c|}
\hline Instance & Benefits of releasing code as open source & Risks of releasing code as open source \\
\hline Mozilla/Netscape/AOL & $\begin{array}{l}\text { - Established partnerships with vendors including IBM, Sun } \\
\text { and Red Hat who also contribute to the development of the } \\
\text { code } \\
\text { - Netscape/AOL remains the major contributor } \\
\text { - Switched to a GPL-compatible triple license scheme to } \\
\text { attract more contributors }\end{array}$ & $\begin{array}{l}\text { - Code was too difficult for external developers to understand when it was } \\
\text { released } \\
\text { - Microsoft reacted by improving IE } \\
\text { Open source offering took the market of commercial offering (Netscape } \\
\text { browser lost market share to Mozilla-based browser) } \\
\text { The conflict between Netscape's business priorities and the Mozilla's } \\
\text { priorities (Mozilla could not result the release of Netscape browser on time) } \\
\text { External developers had the perception that Mozilla is still "Netscape } \\
\text { project" } \\
\text { - Netscape had to give up the profits it generated from direct selling }\end{array}$ \\
\hline Darwin/Apple & $\begin{array}{l}\text { - Pooled talents to enhance and customize the code } \\
\text { - Darwin is special for Apple's hardware } \\
\text { - Apple remains the major contributor and controls Darwin }\end{array}$ & $\begin{array}{l}\text { Developers found it difficult to contribute because the development process } \\
\text { is not open and transparent }\end{array}$ \\
\hline Netbeans/Sun & - Developed partnerships with more than 60 firms & - Developers found it difficult to understand and comply with the changes \\
\hline
\end{tabular}




\begin{tabular}{|c|c|c|}
\hline & $\begin{array}{l}\text { - Competitors such as BEA joined the project } \\
\text { - Sun remains the major contributor }\end{array}$ & taking place because of the lack of transparency in decision-making process \\
\hline OpenOffice.org/Sun & $\begin{array}{l}\text { - Became a major competitor of Microsoft's Office } \\
\text { - Sun remains the major contributor }\end{array}$ & $\begin{array}{l}\text { Users of Microsoft's Office may not switch to OpenOffice.org } \\
\text { Microsoft reacted by lowering price and releasing new translations of } \\
\text { Microsoft Office } \\
\text { The user base grows much faster than the number of developers } \\
\text { - Code was too complex for external developers when it was released } \\
\text { Other communities' fork of the code }\end{array}$ \\
\hline Eclipse/IBM & $\begin{array}{l}\text { Over } 100 \text { partners joined the open source project } \\
\text { - Competitors such as BEA and Borland became strategic } \\
\text { members of the community } \\
\text {-Vendors consider it is costly effective to build their } \\
\text { products on one dominant codebase } \\
\text { - IBM remains the major contributor } \\
\text { - Developed commercial friendly license to attract more } \\
\text { commercial firms } \\
\text { - Became the dominant Java IDE }\end{array}$ & $\begin{array}{l}\text { IBM was suspected by external developers and firms of trying to control } \\
\text { Eclipse to its favor } \\
\text { - Challenges of managing the growth of the project }\end{array}$ \\
\hline
\end{tabular}




\begin{tabular}{|l|l|l|}
\hline OpenSolaris/Sun & $\begin{array}{l}\text { Expanded the number of Solaris users } \\
\text { Sun remains the major contributor }\end{array}$ & $\begin{array}{l}\text { The GPL-incompatible license could mean Solaris-Linux barrier } \\
\cdot \text { Risk of losing profits (code release move has driven Sun into a support and } \\
\text { service revenue model as opposed to the proprietary model of selling } \\
\text { software) }\end{array}$ \\
\hline
\end{tabular}

